\title{
Potential vorticity perspective of the genesis of a Tibetan Plateau vortex in June 2016
}

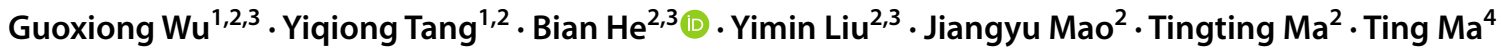

Received: 25 August 2021 / Accepted: 7 December 2021 / Published online: 31 January 2022

(c) The Author(s) 2021

\begin{abstract}
At midnight on 27-28 June 2016, a Tibetan Plateau (TP) Vortex (TPV) generated over the western TP that subsequently caused a downstream record-breaking rainstorm and extremely severe natural disaster. Based on reanalysis data and satellite imagery, this study investigates the formation of this TPV from a potential vorticity (PV) perspective. Results show that, in late June 2016, a remarkable circulation anomaly occurred over the TP and its peripheral area, with easterly flow in the middle and lower troposphere developing in the subtropical zone, replacing the normal westerly flow there. Its forefront merged with the southwesterly flow from the west and penetrated and converged over the western TP where the surface was warmer than normal, forming a low-level jet and downward slantwise isentropic surfaces in-situ. When the air parcel slid down the slantwise isentropic surface, its vertical relative vorticity developed owing to slantwise vorticity development associated with PV restructuring. At the same time, the penetrating southwesterly flow brought abundant water vapor to the western TP and induced increasing sub-cloud entropy and air ascent there. Low-layer cloud formed and the cloud liquid water content increased. The strong latent heat that was released in association with the formation of cloud produced strong diabatic heating near $400 \mathrm{hPa}$ at night and strong PV generation below. The normal diurnal variation was interrupted and the vortex was generated near the surface. These results demonstrate that, against a favorable circulation background, both adiabatic and diabatic PV processes are crucial for TPV genesis.
\end{abstract}

Keywords Tibetan plateau vortex (TPV) - Slantwise vorticity development (SVD) - Moist process · Potential vorticity generation · Diurnal cycle

\section{Introduction}

During the summer of 2016, abnormal heavy rainfall persisted over southern China. In particular, the area in the mid-

Submitted to Climate Dynamics on August 23, 2021.

Bian $\mathrm{He}$

heb@lasg.iap.ac.cn

$\triangle$ Yimin Liu

lym@lasg.iap.ac.cn

1 School of Atmospheric Sciences, Nanjing University of Information Science and Technology, Nanjing 210044, China

2 State Key Laboratory of Numerical Modelling for Atmospheric Sciences and Geophysical Fluid Dynamics (LASG), Institute of Atmospheric Physics, Chinese Academy of Sciences, Beijing 100029, China

3 University of Chinese Academy of Sciences, Beijing 100049, China

4 Hebei Meteorological Bureau, Shijiazhuang 050021, China dle and lower reaches of the Yangtze Basin received recordbreaking weekly rainfall of more than $500 \mathrm{~mm}$ at several stations in late June and early July (Shao et al. 2018; Zhang et al. 2021). This extremely intense rainfall led to the most severe flood disaster since 1998, affecting about 34 million people (Sun et al. 2017) and causing at least US $\$ 22$ billion in economic losses, "making it the second most expensive weather-related natural disaster in China" since 1950 (Zhou et al. 2018).

The occurrence of persistent torrential rain in southern China has long been a key research topic owing to its significant socioeconomic impacts (Tao 1980). Synoptic studies have reached a consensus that the main weather systems that directly contribute to its occurrence come from eastern Asia-namely, cold intrusions from the north, shifts in the 
subtropical anticyclone over the northwestern Pacific from the east, monsoon surges from the south, and meso- $\alpha$ lowpressure perturbations from the west via the Tibetan Plateau (TP) (Zhang et al. 2002, 2003; Tao and Wei 2007; Chen et al. 2020; Wu et al. 2020). In addition to these adjacent weather systems, the torrential rainfall over southern China in the summer of 2016 was regulated by the Madden-Julian Oscillation from the tropics (Shao et al. 2018) and the atmospheric quasi-biweekly oscillations over the TP (Zhang et al. 2021), and attributed to the impacts of the strong 2015/16 El Niño event and external forcing including global warming (Zhou et al. 2018). By diagnosing the most intense torrential rainfall episode along the middle and lower reaches of the Yangtze River, which evolved from 29 June to 1 July, Ma et al. (2020) demonstrated that the development of this episode was associated with a TP vortex (TPV) which appeared during the middle of the night on 27-28 June over the western TP and its subsequent eastward movement. As the TPV propagated eastwards from the TP to the lower reaches of the Yangtze River, the advection of potential vorticity (PV) increased with height in the lower troposphere and provided a large-scale circulation background for the development of rapid air ascent, leading to the in-situ heavy precipitation. They also found that the TPV was formed when there was low cloud but no precipitation, and suggested that the development of low cloud is important to the formation of the TPV. However, how the low cloud developed and what roles it plays in the TPV genesis are unrevealed. This study will shed lights on these issues from the PV perspective.

TPVs are low-pressure cyclones generated at $500 \mathrm{hPa}$ over the TP with an $\alpha$-scale of $400-800 \mathrm{~km}$ in the horizontal and $2-3 \mathrm{~km}$ in the vertical direction. They mostly originate over the highly elevated TP (Ye and Gao. 1979; Lhasa Workgroup 1981; Feng et al. 2014; Curio et al. 2019; Lin et al. 2020), with a warm center and vorticity maximum at $500 \mathrm{hPa}$ (Feng et al. 2017). Associated with the prominent diurnal variation of atmospheric circulation over the highly elevated surface, considerably more TPVs are generated at night than during daytime (Li et al. 2014a, 2018a; Curio et al. 2019; Lin et al. 2020). Due to their significant impacts on local and regional weather and climate, the generation and development of TPVs have received continuous attention, and a series of studies have focused on the relevant mechanisms. Based on a 10-yr climatology of TPVs using NCEP Climate Forecast System reanalysis data, Feng et al. (2014) and Li et al. (2014b, 2018b) identified several favorable large-scale circulation conditions for the genesis of TPVs, including convergence at $500 \mathrm{hPa}$ associated with southerlies from the monsoon trough over the Bay of Bengal and northwesterly flow from the westerly zone, and divergence at $200 \mathrm{hPa}$ associated with the westerly jets and South Asian high (SAH).
At the same time, numerous studies have emphasized the significant roles played by regional and local diabatic heating in TPV genesis, in which the importance of surface sensible heating has been particularly underlined (e.g., Shen et al. 1986; Li and Zhao 2002; Tian et al. 2015; Wu et al. 2018a, b). Based on a case study, Luo et al. $(1991,1992)$ found that the inhomogeneity of surface heating is conducive to an increase in eddy effective-potential energy and kinetic energy, which favors TPV genesis. By assuming the TPV to be a tropical-cyclone-like vortex, Li and Zhao (2002) investigated the role of surface sensible heating in the structure and intensification of TPVs, and found that the significance of surface sensible heating depends on the relative location of the flow and heating fields. On the other hand, the impacts on TPV genesis of the latent heating associated with precipitation have also been highlighted (Wang 1987; Li et al. 2011; Zhang et al. 2019). In a case study, Li et al. (2011) compared the apparent heat source (Q1) with the apparent moisture sink (Q2) defined by Yanai et al. (1992) and found that the vertical profiles of Q1 and Q2 were similar during the TPV formation process, implying the dominance of latent hating in the diabatic processes during TPV genesis. Results from numerical experiments indicate that the relative importance of different kinds of heating during TPV genesis and development is case-dependent (Tian et al. 2015; Wu et al. 2018a, b).

Despite the progress in understanding TPV genesis, several fundamental issues remain unclear. For instance, given that the thermal diurnal cycle exists continuously over elevated surfaces from day to day, why does TPV genesis only occur on certain days and in limited numbers? Also, although the latent heating associated with precipitation is important to TPV genesis, why sometimes are TPVs generated without the involvement of precipitation? $\mathrm{Li}$ and Zhao (2002) indicated that both circulation and diabatic heating are important for TPV genesis. Based on a case study, Ma et al. (2020) demonstrated that the variation in the vertical heating profile near the surface is also critical for TPV genesis because it is directly linked to the generation of in-situ PV. These results imply that PV diagnosis can be an effective tool for understanding TPV genesis because it combines both dynamical and thermal elements, and because the PV budget equation involves both diabatic heating and frictional dissipation, which is appropriate for the diagnosis of an open-dissipative system such as the TPV. For an adiabatic and frictionless system, PV is conserved. Even so, circulation can still change dramatically owing to the so-called "PV restructuring" (Wu et al. 2020): changes in density, baroclinity, static stability, or horizontal vorticity can lead to the change in vertical vorticity. In the case of the TPV genesis that occurred on 27 June 2016 studied by Ma et al. (2020), there was no rainfall before the vortex was formed. Therefore, in addition to the generation of PV associated with 
diabatic processes, the formation of this TPV may be at least partly interpretable by the restructuring of PV. Accordingly, this study investigates TPV genesis from a PV perspective based on data diagnosis.

The remainder of the paper is organized as follows: Sect. 2 describes the data and method used for this study. Section 3 evaluates the atmospheric circulation during late June 2016, with detailed analysis before the TPV genesis at 0000 local time (LT) 28 June. Section 4 focuses on the atmospheric thermal structure over the area where the TPV formed, and diagnoses the adiabatic vorticity development associated with the TPV genesis from the perspective of restructured PV. In Sect. 5, by investigating the evolution of the moist process associated with cloud formation, the contribution of the diurnal cycle of the vertical heating profile to the PV generation related to the TPV genesis is revealed. Finally, a brief summary and discussion are presented in Sect. 6.

\section{Data and method}

Two datasets are employed in this study. The Modern-Era Retrospective Analysis for Research and Applications dataset, version 2 (MERRA2; Gelaro et al. 2017) from NASA is used for synoptic diagnosis, which is accessible at https:// disc.gsfc.nasa.gov/datasets?project=MERRA-2. This dataset possesses a horizontal resolution of $0.5^{\circ} \times 0.625^{\circ}$ at 42 isobaric levels with a three-hourly interval. Meteorological variables provided include horizontal wind, vertical velocity, air temperature, pressure, specific humidity, cloud liquid water content (CLWC), and diabatic heating rate and its components. It has been verified to be reliable in capturing TPVs and delineating circulations over the TP (Lin et al. 2020; Ma et al. 2020). To depict the cloud condition, the brightness temperature data from the FY-2 geostationary meteorological satellite E of the National Satellite Meteorological Center (http://www.nsmc.org.cn/en/NSMC/Home/ Index.html) are also employed, which provide high-resolution visible and infrared data with a 30-min time interval. The FY-2E satellite was launched in December 2008 and was located at $105^{\circ} \mathrm{E}$. In July 2015 , it drifted from $105^{\circ} \mathrm{E}$ to $86.5^{\circ} \mathrm{E}$, just over the $\mathrm{TP}$, and can thus provide efficient information on cloud-system movement over the TP. Infraredband datasets are retrieved for nighttime cloud detection and the threshold is judged based on the difference in brightness temperature $\left(T_{B}\right)$ between cloud and non-cloud conditions, wherein the lower the $T_{B}$, the higher the cloud-top height. We take the following threshold algorithm to classify different kinds of cloud:

- $T_{B} \geq 270.5 \mathrm{~K}$, clear sky;

- $270.5 \mathrm{~K}>T_{B} \geq 260.0 \mathrm{~K}$, low cloud;
- $260.0 \mathrm{~K}>T_{B} \geq 250.0 \mathrm{~K}$, middle cloud; and

- $250.0 \mathrm{~K} \geq T_{B}$, high cloud.

\section{Role of large-scale circulation in the TPV's genesis}

A favorable circulation background is fundamental for TPV genesis. Here, MERRA-2 reanalysis data are employed to reveal the characteristics of the anomalous circulation in late June 2016 and to identify its contribution to the TPV's genesis.

\subsection{Evolution of large-scale circulation in late June 2016}

Previous studies have shown that TPV genesis is inextricably linked with large-scale circulation (Li et al. 2011, 2014b, 2018b). To investigate the evolution of the background circulation in the present case, Fig. 1 presents the evolution of geopotential height and wind in the upper troposphere at $250 \mathrm{hPa}$ in late June 2016 compared to the climate mean for the same period averaged between 1980 and 2019. In the climatology (Fig. 1a), westerly flow prevails in the midlatitude zone, and the center of the SAH is located to the south of the TP. The area over the TP is dominated by westerly flow, and the tropical easterly flow is located to the south of $25^{\circ} \mathrm{N}$. In late June 2016, prominent troughs and ridges were meandering along the midlatitude westerlies (Fig. 1b-e), and the SAH was much stronger than in the climatology which is characterized by the occurrence of geopotential contours higher than 11,050-gpm, and migrated northwards with its center located over the TP after 25 June (Fig. 1d, e). Correspondingly, the tropical easterly jet was shifted northwards to the north of $25^{\circ} \mathrm{N}$, which was conducive to the northward development of the tropical easterly flows in the middle and lower troposphere, as will be shown below.

At $500 \mathrm{hPa}$, westerly flow also prevails in the extratropics in the climate mean (Fig. 2a). Along the subtropics, the westerlies split over the western TP and converge over the central and eastern TP. In the tropics, while anticyclonic circulation dominates over the northwestern Pacific and Middle East area, a strong trough is located over the North Indian Ocean and Indian subcontinent. In late June 2016, however, a remarkable circulation anomaly occurred. In the midlatitudes, the flat westerly flow on 21 June (Fig. 2b) subsequently changed to a fluctuating flow (Fig. 2c-e). By the time the TPV was about to form, a prominent deep trough was located just to the west of the TP, with strong southwesterly flow sweeping over the western end of the TP. Prominent anomalous circulation developed in the tropics. The monsoon trough over the North Indian Ocean in the climate mean (Fig. 2a) was cut-off, and an isolated anomalous 

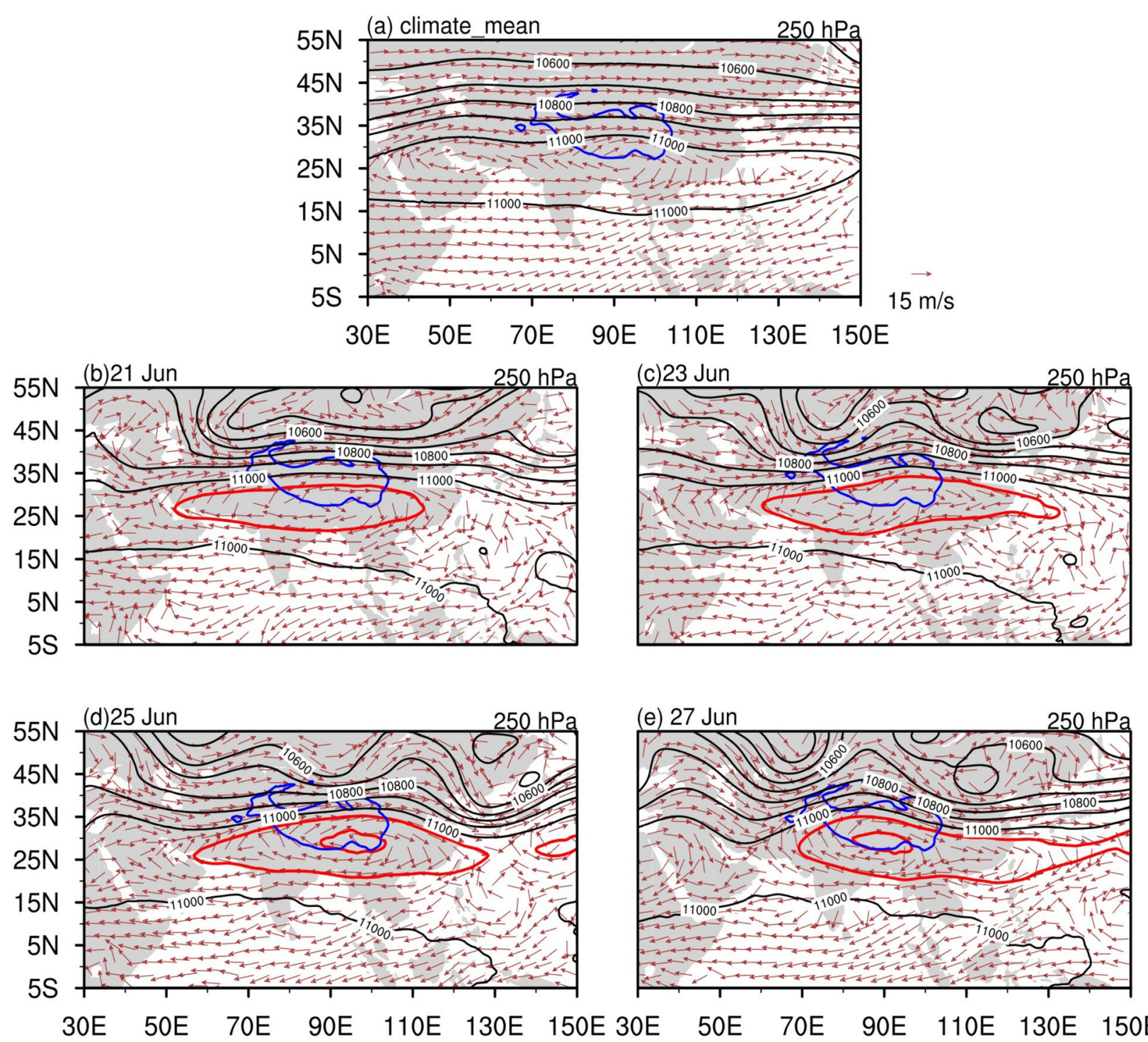

(e) 27 Jun

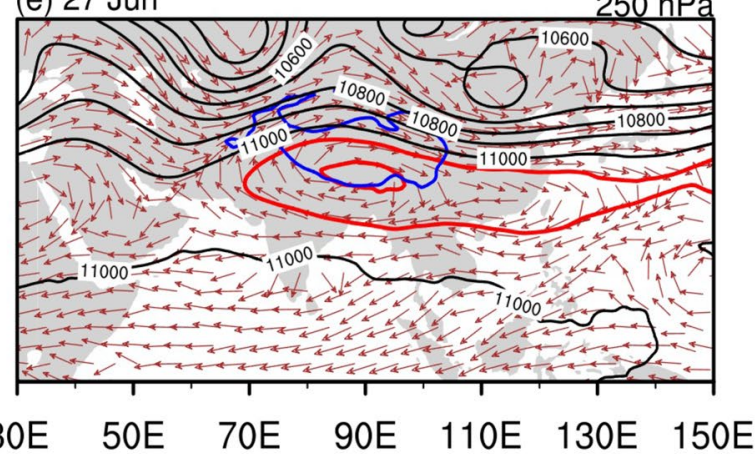

Fig. 1 Distributions of geopotential height (thick contours; units: $\mathrm{gpm}$ ) and horizontal wind (vectors; units: $\mathrm{m} \cdot \mathrm{s}^{-1}$ ) at $250 \mathrm{hPa}$ for (a) the June 21-30 climatology averaged between 1980 and 2019, b 21

cyclonic circulation gyre occupied the area from the Arabian Sea to the Bay of Bengal, which migrated gradually northwards, leading to the northward development of easterly flow to the south of the TP (Fig. 2b-e). At the same time, the subtropical anticyclone characterized by the 5880 -gpm contour developed and extended westwards much stronger than normal. Before 25 June 2016, the westernmost point of the subtropical high had already reached $110^{\circ} \mathrm{E}$ (Fig. 2d). By June 27 , it had arrived at $90^{\circ} \mathrm{E}$ - the longitude where the eastern end of the tropical cyclonic gyre was located (Fig. 2e). A strong anomalous easterly jet near $25^{\circ} \mathrm{N}$ from the northwestern Pacific to northwestern India thus formed between the tropical cyclonic gyre and the subtropical anticyclone. The western end of this easterly jet merged with
June 2016, c 23 June 2016, d 25 June 2016, and e 27 June 2016. The thick red contour denotes the geopotential height of 11,050 gpm. The thick blue contour indicates the elevation of $3000 \mathrm{~m}$

the trough that had developed over the western TP, which caused the easterly wind to turn into southwesterly flow that penetrated the western TP.

The climate mean geopotential height and wind fields at $700 \mathrm{hPa}$ (Fig. 3a) are similar with their counterparts at $500 \mathrm{hPa}$ (Fig. 2a), except that the convergence to the TP of the peripheral flows becomes more evident. In late June 2016, the development of synoptic-scale waves along the westerly flow in the midlatitudes and the remarkable westward extension of the northwestern Pacific subtropical anticyclone were also similar with the situation at $500 \mathrm{hPa}$ (Fig. 3b-e). The distinctive circulation configuration at $700 \mathrm{hPa}$ was the development of tropical vortices over the Arabian Sea and the Bay of Bengal. On 21 June (Fig. 3b), 

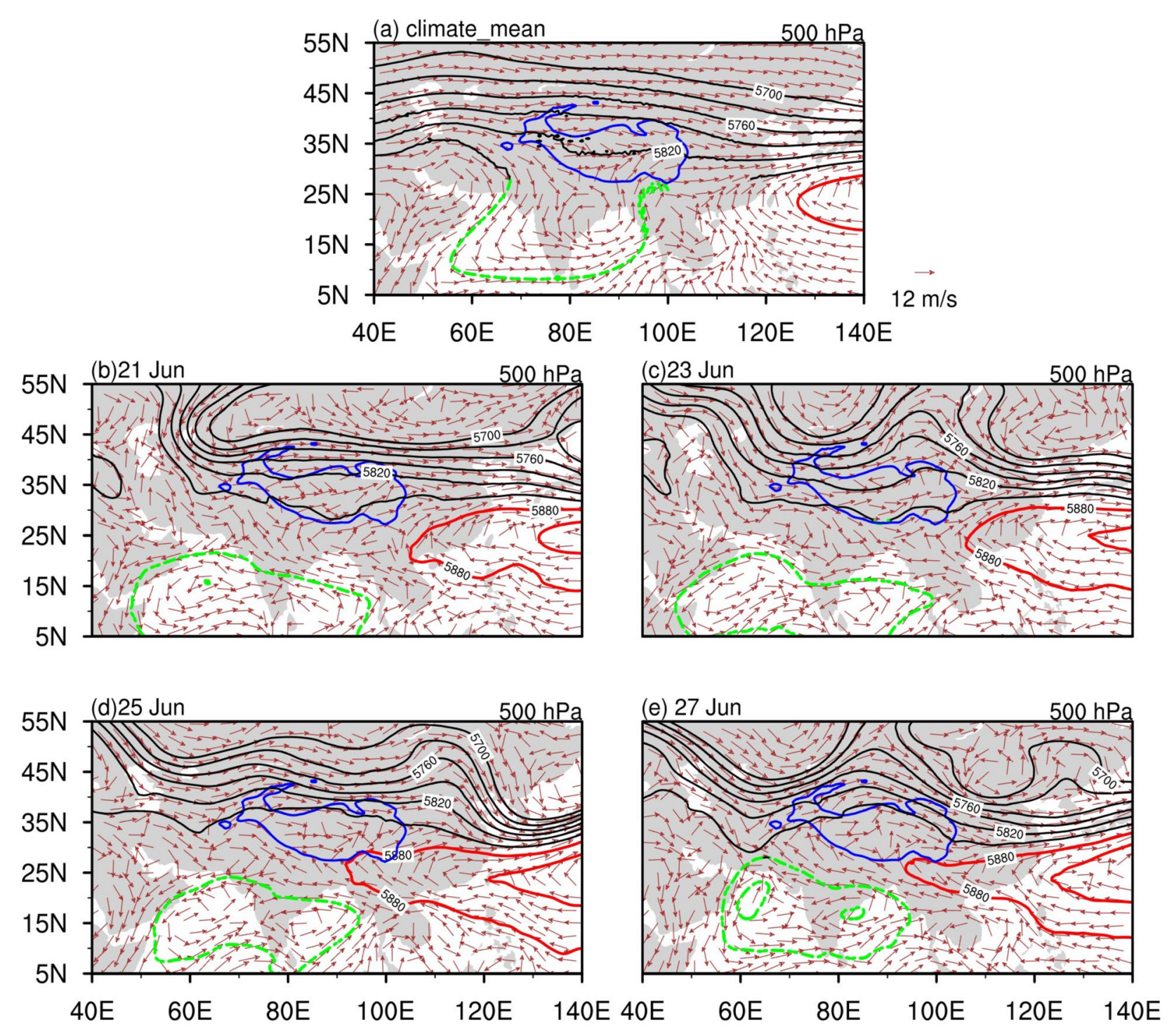

Fig. 2 As in Fig. 1 but for $500 \mathrm{hPa}$. The thick red contours denote geopotential height exceeding 5880 gpm. The area lower than $5850 \mathrm{gpm}$ is encircled by the dashed green contour

a tropical vortex formed in the Arabian Sea first, and the other vortex over the Bay of Bengal had generated by 25 June (Fig. 3d). The two low-level vortices migrated northwards gradually and formed a prominent cyclonic gyre with twin vortex centers over South Asia by 27 June. The original westerly flow surrounding the southern peripheral boundary of the TP (Fig. 3b, c) was finally replaced by southeasterly flow (Fig. 3e).

\subsection{Circulation anomaly before the TPV's genesis}

Favorable evolution of atmospheric circulation only provides the necessary condition for TPV formation. A sufficient condition for TPV genesis requires specific dynamic and thermodynamic circumstances. To understand the specific weather condition that favored the TPV generation in the present case, we next focus on the circulation and temperature anomalies during the period just before the TPV genesis. Figure 4 presents the distributions of atmospheric circulation, relative vorticity, and temperature at $500 \mathrm{hPa}$ over the TP and its periphery. For comparison, the June climatemean circulation and temperature averaged from 1980 to 2019 are presented in Fig. 4a and e, respectively. As in late June (Fig. 2a), the mean circulation in June is characterized by the westerly flow meandering over the TP and a detour appearing in the western part of the plateau (Fig. 4a). A deep trough develops to the south of the TP over the Bay of Bengal. Airflow converges near $35^{\circ} \mathrm{N}$ from the western to central $\mathrm{TP}$, producing a belt of positive relative vorticity that favors TPV generation (Li et al. 2014b; Curio et al. 2019; Lin et al. 

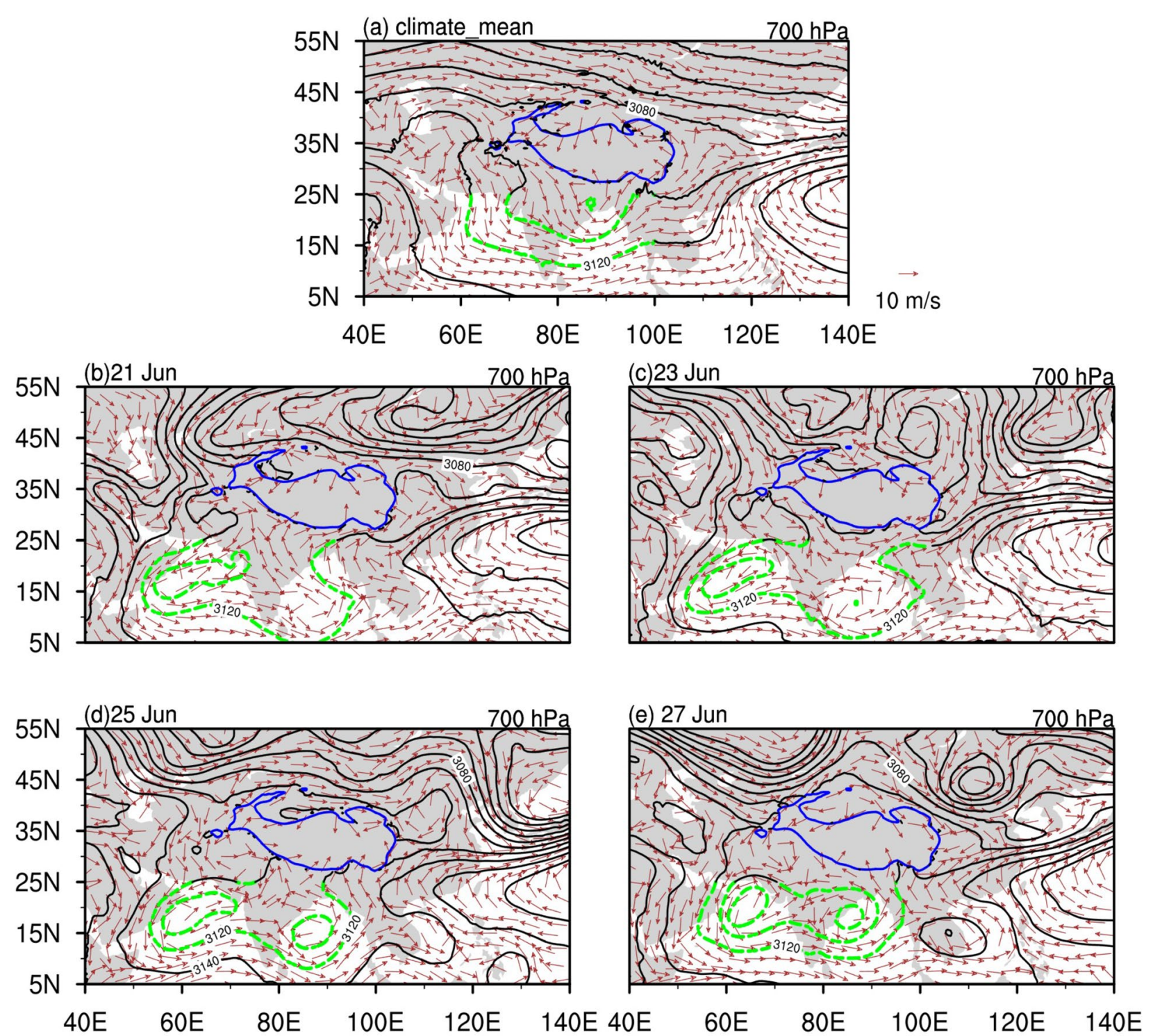

Fig. 3 As in Fig. 1 but for $700 \mathrm{hPa}$. The green dashed contours denote geopotential height lower than 3120 gpm over the northern Indian Ocean

2020). Meanwhile, the warm area covers the southern TP and Asian monsoon region (Fig. 4e).

In late June 2016, dramatic circulation anomalies appeared in the build-up to the TPV's genesis. At 1800 LT (at $90^{\circ} \mathrm{E}$ - the same hereafter) 26 June, before the development of the TPV, the midlatitude westerly flow meandered with two troughs located upstream and downstream of the $\mathrm{TP}$ and a ridge to its north (Fig. 4b). At the same time, the cyclonic circulation was developing over the Arabian Sea, the Bay of Bengal, and the South China Sea. As the subtropical anticyclone over the northwestern Pacific and tropical cyclones gradually migrated northwards, a tropical easterly jet was located at $20^{\circ} \mathrm{N}$ to their north. Between the westerly in the midlatitudes and the easterly jet in the tropics, there was a prominent belt of anticyclonic circulation extending from central Asia to southeastern China. The southwestern TP was controlled by anticyclonic circulation, with easterly flows penetrating out of its southwestern boundary towards the cyclonic circulation over the Arabian Sea. At the same time, a strong warm center at $500 \mathrm{hPa}$ appeared over the western TP (Fig. 4f). The development of the near-surface warm center over the western TP was important to the development of the in-situ cyclonic vorticity, as will be discussed below.

The third row and bottom row in Fig. 4 represent, respectively, the distributions of circulation and temperature during the development and formation stage of the TPV, which is circled in Fig. 4c, d, g and h. During the development phase at 1800 LT 27 June (Fig. 4c), as the tropical cyclones strengthened over the Arabian Sea and Bay of Bengal, two 

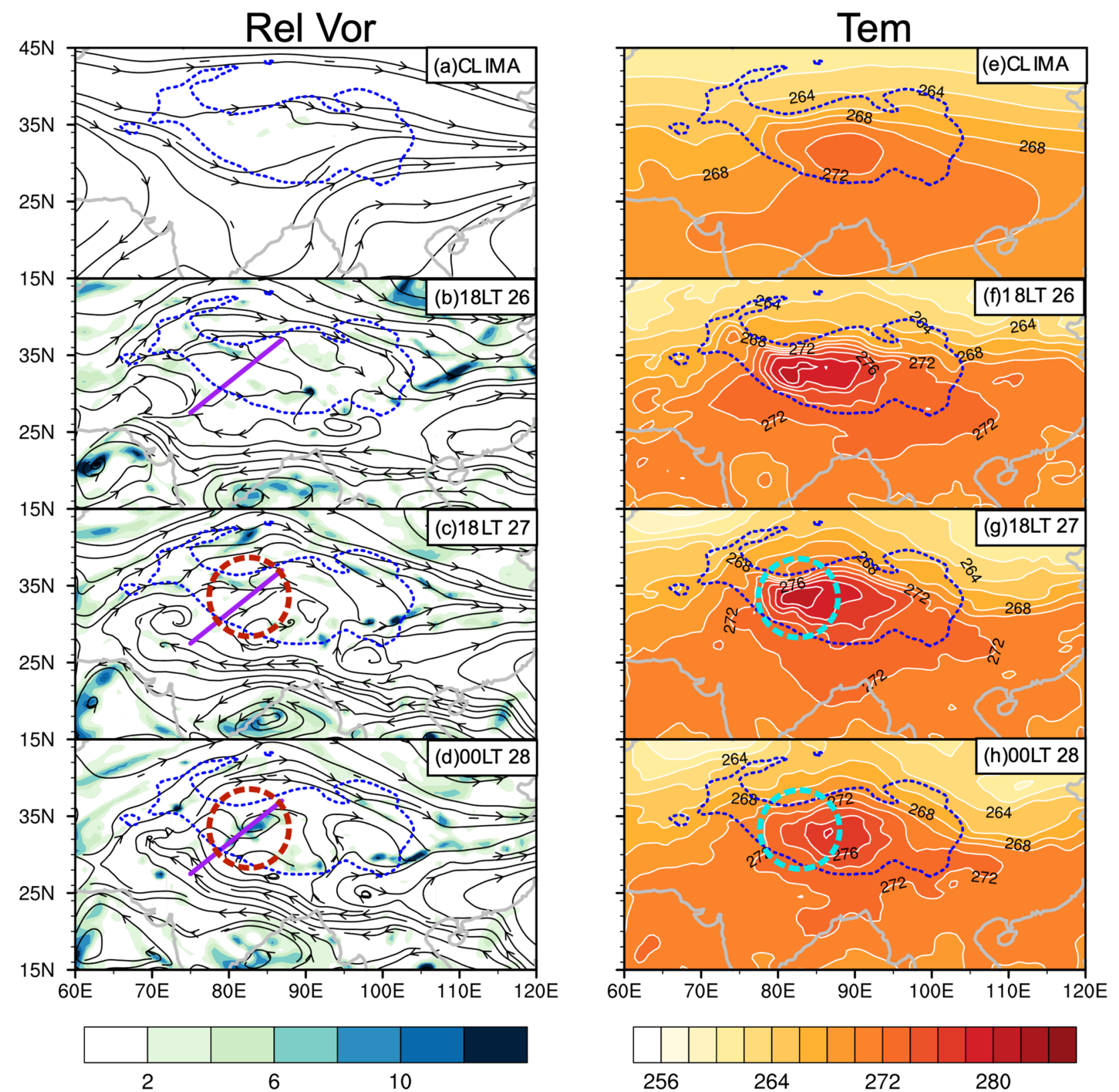

Fig. 4 Distributions at $500 \mathrm{hPa}$ of (a-d) streamlines and relative vorticity (shading; units: $10^{-5} \mathrm{~s}^{-1}$ ), and (e-h) temperature (shading; units: K), for (a, e) the June 21-30 climatology averaged between 1980 and 2019, (b, f) 1800 LT 26 June, (c, g) 1800 LT 27 June, and

anticyclone centers developed to their north near to $30^{\circ} \mathrm{N}$ owing to horizontal inhomogeneous diabatic heating (Liu et al. 1999). Thereby, the tropical easterly jet was intensified, and its western and central portion moved northwards remarkably, with its forefront merging with the approaching midlatitude westerly trough and southerly flow developing over central Asia. Consequently, westerly flow and southwesterly flow penetrated the southwestern TP and converged there, leading to the development of positive relative (d, h) 0000 LT 28 June. The dotted blue contour indicates the area over $3000 \mathrm{~m}$. The dashed circle in $(\mathbf{c}, \mathbf{d}, \mathbf{g}$, and $\mathbf{h})$ denotes the area surrounding the TPV's genesis site which is at the center of the circle. The purple line denotes the location of the cross section used below

vorticity over the northwestern TP where the warm center intensified concurrently (Fig. 4g). By 0000 LT 28 June (Fig. 4d), the tropical easterly jet had enhanced and migrated further north. As the eastward-moving westerly trough was located just to the west of the TP, the southerly flows that crossed the southern border of the TP and penetrated its interior developed and converged further as well. A prominent smaller-scale TPV with strong cyclonic circulation and vorticity was formed at Site V over the northwestern TP where 


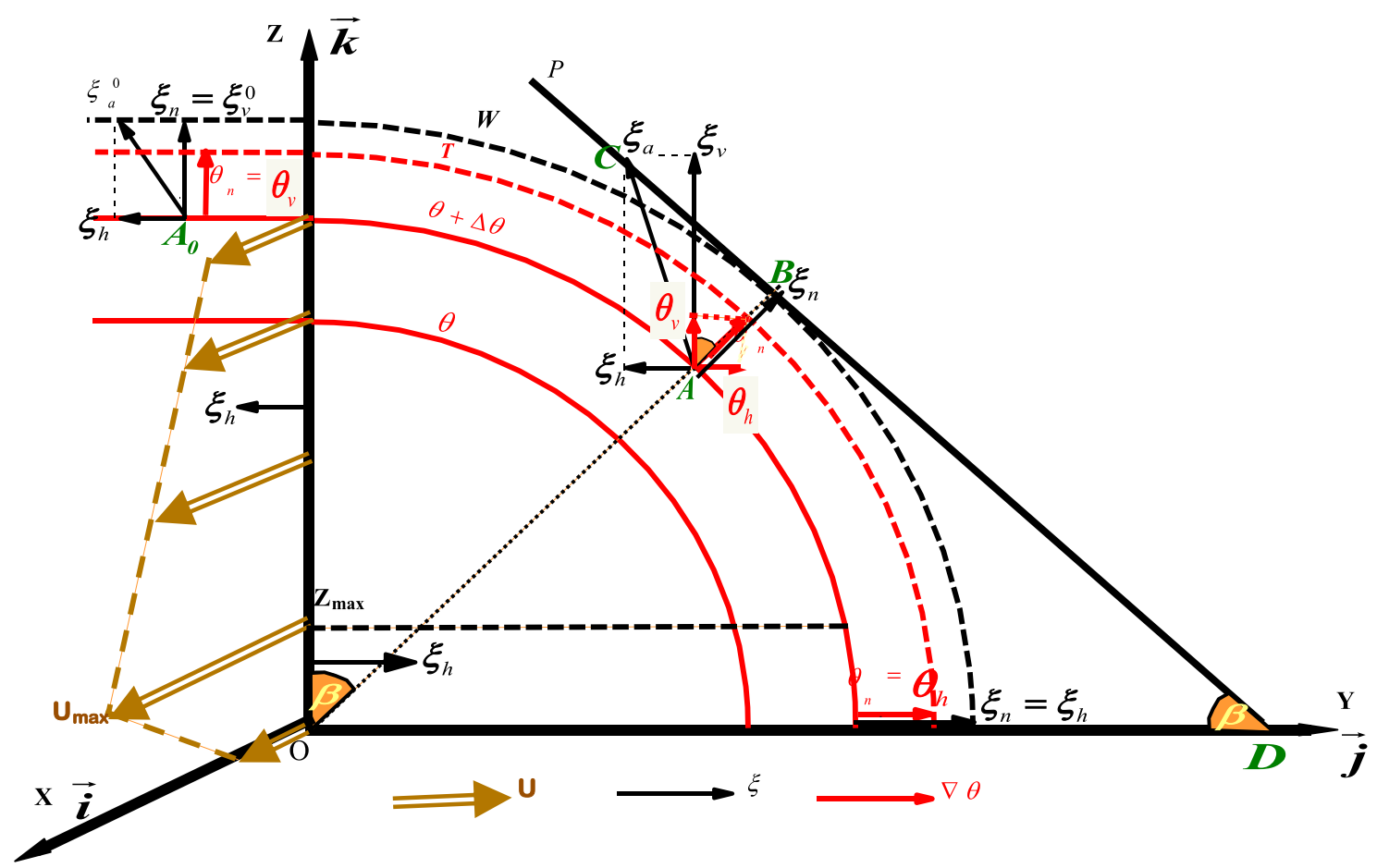

Fig. 5 Schematic diagram showing the vertical vorticity development on the slantwise isentropic surface $\theta+\Delta \theta$ in a dry and static-stable atmosphere. When a parcel at position $A_{0}$ with $P=\xi_{n}^{0} \theta_{n}$ initially

the warm center had persisted (Fig. 4g, h). The TPV was thus embedded at the center of the large-scale anticyclonic circulation surrounding the TP.

\section{Slantwise vorticity development and PV restructuring}

Although the synoptic evidence for the occurrence of the TPV is clear, the dynamic mechanism for its generation has not yet been elucidated. Since there was no precipitation during the TPV's genesis, the adiabatic dynamic mechanism is explored first in this section from the PV perspective.

\subsection{Adiabatic slantwise vorticity development}

When an air parcel moves adiabatically on a slantwise isentropic surface and satisfies certain conditions, its vertical vorticity can develop, which is termed as slantwise vorticity development (SVD) (Wu et al. 1995; Wu and Liu 1997). SVD has been successfully used to interpret the rapid development of torrential rain associated with the mei-yu front (e.g., Liu and Zhang 1996) and the genesis of the Southwest Vortex (Wu and Liu 1997, 1999). Here, following Wu and Liu (1997) we use SVD to understand how the TPV developed adiabatically. slides down the isentropic surface to point $A$ at a slantwise angle $\beta$, the increase in $\beta$ leads to the vertical vorticity development. See text for details. Refer to Wu and Liu (1997)

The celebrated PV equation (Ertel 1942; Hoskins et al. 1985) is

$\left\{\begin{array}{l}\frac{d P}{d t}=\alpha\left[\vec{\zeta}_{a} \cdot \nabla \dot{\theta}+\nabla \times \vec{F} \cdot \nabla \theta\right] \\ P=\alpha \vec{\zeta}_{a} \cdot \nabla \theta\end{array}\right.$

where $P$ denotes $\mathrm{PV}, \alpha$ is specific volume, $\vec{\zeta}_{a}$ is $3 \mathrm{D}$ absolute vorticity, $\vec{F}$ is the frictional acceleration in the momentum equation, and $\nabla$ is a 3D gradient operator. Equation (1) indicates that $\mathrm{PV}$ is conserved for adiabatic and frictionless atmospheric motions.

Consider an adiabatic and frictionless atmosphere. Decompose $\nabla \theta$ and $\alpha \vec{\zeta}_{a}$ to their vertical and horizontal components,

$\left\{\begin{array}{c}\nabla \theta=\theta_{\mathrm{n}} \vec{n}=\theta_{\mathrm{v}} \vec{k}+\theta_{\mathrm{h}} \vec{j} \\ \alpha \overrightarrow{\zeta_{a}}=\xi_{n} \vec{n}=\xi_{\mathrm{v}} \vec{k}+\xi_{\mathrm{h}} \vec{j}\end{array}\right.$

in which $\alpha \overrightarrow{\zeta_{a}}=\xi_{n} \vec{n}$ is specific absolute vorticity, and $\overrightarrow{\mathrm{j}}$ and $\vec{k}$ are the unit vectors in Cartesian coordinates $(\overrightarrow{\mathrm{i}}, \overrightarrow{\mathrm{j}}, \overrightarrow{\mathrm{k}})$ with $\vec{k}$ pointing upwards and $\vec{j}$ along the horizontal gradient of potential temperature (Fig. 5). Then,

$P=\alpha \vec{\zeta}_{a} \cdot \nabla \theta=\xi_{\mathrm{n}} \theta_{n}=\xi_{v} \theta_{v}+\xi_{h} \theta_{h}=$ const. 
(a) $06 / 2618 \mathrm{LT}$

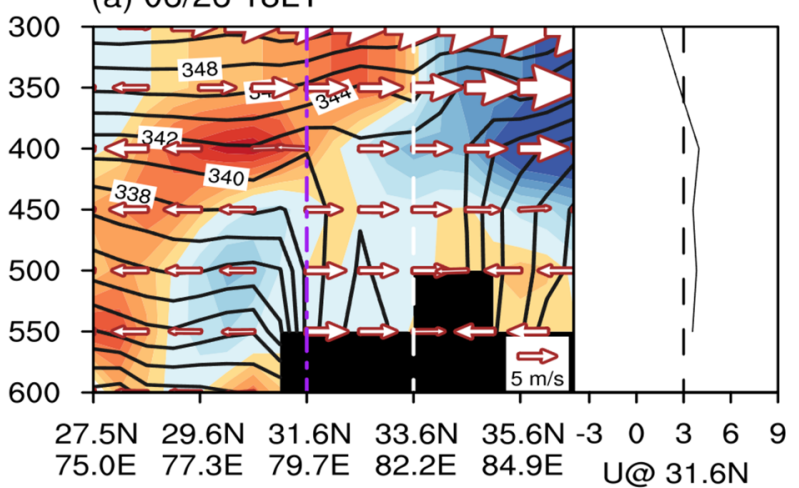

(b) $06 / 2718 \mathrm{LT}$

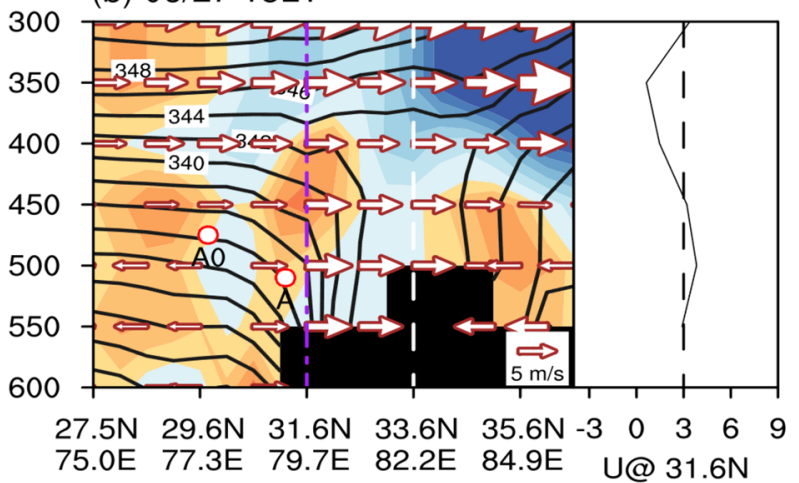

(c) $06 / 2800 \mathrm{LT}$
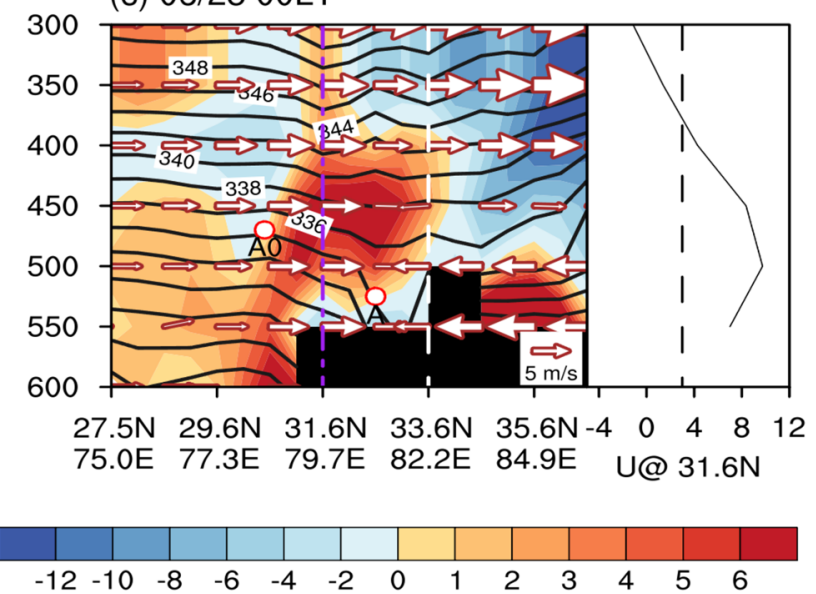

Fig. 6 Cross section of potential temperature (black contours; units: $\mathrm{K}$ ) and horizontal vorticity (shading; units: $\mathrm{m} \cdot \mathrm{s}^{-1} \mathrm{~Pa}^{-1}$ ) and wind (white vectors; units: $\mathrm{m}^{\cdot \mathrm{s}^{-1}}$ ) at a 1800 LT 26 June, b 1800 LT 27 June, and c 0000 LT 28 June along the direction of the purple line depicted in Fig. 4. The right-hand panel is the vertical profile of the horizontal wind $U$ (perpendicular to the cross section) at the location upstream of the vortex as indicated by the purple dot-dashed line in the left-hand panel. The location of the white dashed line represents the vortex center. Black shading shows the surface pressure. $A_{0}$ and $A$ represent the location of the initial and down-sliding point, respectively

and thus
$\xi_{v}=\left[\frac{P}{\theta_{v}}-\frac{\xi_{h} \theta_{h}}{\theta_{v}}\right], \theta_{v} \neq 0$

For easy understanding, the relations among the various variables in Eq. (4) are shown schematically and ideally in Fig. 5, in which the contours $\theta, \theta+\nabla \theta, \mathrm{T}$, and $W$ are parallel to each other and horizontally located for $Y<0$ and cycloidal for $Y>0$. The distribution for $\theta$ and $\theta+\nabla \theta$ mimics the potential temperature distribution upstream of the TPV before its formation, as shown in Fig. $6 \mathrm{~b}$ and c. The distance between contours $\theta+\nabla \theta$ and $T$ is equal to $\left|\theta_{\mathrm{n}}\right|$; whereas, the distance between contours $\theta+\nabla \theta$ and $W$ is equal to $\left|\xi_{\mathrm{n}}\right|$. This, according to Eq. (3), provides a background for the conservation of PV in which $\theta_{\mathrm{n}}$ and $\xi_{\mathrm{n}}$ are both unchanged when an air parcel slides down the potential temperature surface $(\theta+\nabla \theta)$ from $\mathrm{A}_{0}$ to A. A low-level jet with $U_{\max }$ is located at $Z_{\max }$, and a constant negative $\xi_{h}(=\alpha \cdot \partial U / \partial z)$ above $Z_{\max }$ is assumed. Line $\overline{\mathrm{PD}}$ is tangential with the cycloid $W$ at point $\mathrm{B}$, and the slantwise angle $\beta(=\angle \mathrm{BDO}=\angle B O Z)$ measures the degree of deviation of the radius $\overline{\mathrm{OA}}$ from the vertical axis $\overline{\mathrm{OZ}}$. According to Fig. 5, we have $\tan \beta=\frac{\theta_{h}}{\theta_{v}}$ and $\frac{1}{\cos \beta}=\frac{\theta_{n}}{\theta_{v}}, 0<\beta<\pi / 2$.

From Eqs. (3) and (4),

$\xi_{v}=\left[\frac{\xi_{\mathrm{n}}}{\theta_{\mathrm{v}} / \theta_{n}}-\xi_{h} \theta_{\mathrm{h}} / \theta_{v}\right]=\left[\frac{\xi_{\mathrm{n}}}{\cos \beta}-\xi_{h} \tan \beta\right], \theta_{v} \neq 0, \beta \neq \pi / 2$.

Because both $1 / \cos \beta$ and $\tan \beta$ increase with increasing $\beta$, the relative vorticity of the parcel moving from $A_{0}$ downwards to $A$ along the slantwise potential temperature surface $\theta+\nabla \theta$ will increase if $C_{d}=\frac{\xi_{h} \theta_{\mathrm{h}}}{\theta_{v}}<0$, or $\xi_{h}<0$, since $\theta_{\mathrm{h}}>0$ and $\theta_{\mathrm{v}}>0$, resulting in SVD. As a matter of fact, since $\theta_{\mathrm{n}}$ and $\xi_{\mathrm{n}}$ are both unchanged during the parcel movement, taking the total derivative on both sides of Eq. (5) leads to

$\frac{d \xi_{v}}{d t}=\frac{1}{\cos ^{2} \beta}\left[\xi_{n} \sin \beta-\xi_{h}\right] \frac{d \beta}{d t}, \beta<\pi / 2$.

For a parcel sliding down the slantwise isentropic surface $\theta+\nabla \theta, d \beta / d t>0$. Therefore, the necessary condition for SVD is

$\zeta_{h}=\frac{\partial U}{\partial z}<\left(f+\zeta_{z}\right) \sin \beta$

i.e., a weak vertical shear of the "zonal wind" $U$; whereas,

$\zeta_{h}=\frac{\partial U}{\partial z}<0$

is a sufficient condition for SVD, i.e., the "zonal wind" $U$ decreases with increasing height. This is to say, when an air parcel slides downwards on a slantwise isentropic surface 
adiabatically from $A_{0}$ to $A$, its vertical vorticity can develop if a low-level jet exists that is perpendicular to $\vec{j}$, i.e., the direction of the horizontal gradient of potential temperature.

Consider an air parcel moving on a horizontally located isentropic surface as shown in Fig. 5 for $\mathrm{Y}<0$. In such case, any change in horizontal specific absolute vorticity $\xi_{h}$ will not affect the vertical specific absolute vorticity $\xi_{v}$. This is because $\theta_{\mathrm{h}}=0$ when the isentrope is horizontally located. Consequently, according to the classical PV definition (Eqs. 1 and 3), the PV conservation ( $P=\alpha \vec{\zeta}_{a} \cdot \nabla \theta=\xi_{\mathrm{n}} \theta_{n}=\xi_{v} \theta_{v}=$ const. $)$ implies that the change of $\xi_{v}$ depends solely on the change of static stability $\theta_{\mathrm{v}}$. In contrast, when an air parcel moving on a slantwise isentropic surface from $A_{0}$ to $A$ as shown in Fig. 5 for $Y>0$, the PV conservation constrain indicates that the arrowhead "C" of specific absolute vorticity $\left(\vec{\xi}_{a}=\alpha \vec{\zeta}_{a}\right)$ should be located on the tangent plane "P" of the "W" surface because $\xi_{\mathrm{n}} \theta_{n}$ at $A$ must equal to that at $A_{0}$. In such a circumstance, the development of $\xi_{v}$ is closely linked to the change in $\xi_{h}$ and the slantwise angle $\beta$, which is refered to SVD. For geostrophic atmsopheric motion, $\xi_{\mathrm{h}} \theta_{h}=-\lambda \theta_{h}^{2}<0$ where $\lambda$ is a positive coefficient. Then the PV conservation becomes $P=\xi_{v} \theta_{v}-\lambda \theta_{h}^{2}=$ const., and an increase in baraclinity $\left(\theta_{\mathrm{h}}\right)$ or a decrease in static stability $\left(\theta_{\mathrm{v}}\right)$ will lead to the development of $\xi_{v}$, in agreement with the SVD as presented in Eq. 5 . Even for ageostrophic atmospheric motion, the nessacery
$400 \mathrm{hPa}$ on both sides of the genesis site $\mathrm{V}\left(33.6^{\circ} \mathrm{N}, 82.2^{\circ} \mathrm{E}\right.$; indicated by the vertical dashed white line) where the TPV formed. This is in accordance with the location of the nearsurface warm center shown in Fig. $4 \mathrm{f}$ and g, indicating the significance of the surface thermal condition in the generation site of the TPV. The air flows below $400 \mathrm{hPa}$ and to the southwestern TP diverged out from the TP on 26 June before the TPV's development (Fig. 6a), which is consistent with the southwestward horizontal circulation shown in Fig. 4b. Strikingly, on 27 June, these airflows suddenly turned to converge towards the TP during the development and formation stages of the TPV (Fig. 6b, c), which is consistent with the northeastward horizontal circulation shown in Fig. $4 \mathrm{c}$ and d. Notice that the isentropic surfaces away from the TP are horizontally distributed, whereas those in the lower troposphere over the TP all tilt downwards and intersect with the TP's surface where the temperature is warmer (Fig. $4 \mathrm{~g}, \mathrm{~h}$ ) - a picture similar to the schematic shown in Fig. 5. Therefore, during the developing and formation stages of the TPV when the air parcel moved adiabatically from $A_{0}$, sliding downwards to $A$ (Fig. $6 \mathrm{~b}, \mathrm{c}$ ), the environmental static stability $\left(\theta_{\mathrm{v}}=\partial \theta / \partial \mathrm{z}\right)$ decreased while the baroclinity $\left(\theta_{\mathrm{h}}=\partial \theta / \partial h\right)$ increased.

Taking the total time-derivative on both sides of Eq. (4) and using Eq. (1) lead to the alternative or complete form of vorticity equation (Wu and Liu 1997, 1999):

$$
\begin{aligned}
& \frac{d \zeta_{\mathrm{v}}}{d t}+\beta v+\left(f+\zeta_{v}\right) \nabla \cdot \vec{V}=-\frac{1}{\alpha \theta_{v}^{2}}\left[\alpha\left(f+\zeta_{v}\right) \theta_{v} \frac{d \theta_{v}}{d t}+\theta_{v}\left(\xi_{h} \frac{d \theta_{h}}{d t}+\theta_{h} \frac{d \xi_{h}}{d t}\right)\right] \\
& +\frac{1}{\theta_{v}} \nabla \theta \cdot \nabla \times \vec{F}+\frac{1}{\theta_{v}} \vec{\zeta}_{a} \cdot \nabla \dot{\theta} \cdot\left(\theta_{v} \neq 0\right)
\end{aligned}
$$

condition (7.1) indicates that SVD may occur so long as the vertical shear of the "zonal wind" $U$ is weak.

\subsection{PV restructuring}

The above discussion provides a mathematical relation between vertical vorticity development and the distributions of circulation and temperature. The underline physics is explored in this sub-Section. Figure 6 is a cross section along the flow direction upstream of the TPV and passing through its center as indicated by the purple line in Fig. 4b-d of potential temperature, the horizontal wind along the cross section, and the horizontal component of vorticity, which is the vertical gradient of the horizontal wind $U$ perpendicular to the cross section. The profile of $U$ at the site indicated by the vertical purple dot-dashed line upstream of the vortex is presented in the right-hand panels of Fig. 6. The outstanding feature of the cross-sections before the TPV's genesis (Fig. 6a, b) is the steeply slantwise isentropic surfaces below
This indicates that, for adiabatic and frictionless atmospheric motion, changes in static stability $\theta_{\mathrm{v}}$, baroclinity $\theta_{\mathrm{h}}$, or wind vertical-shear $\left(\xi_{h}=\alpha \cdot \partial U / \partial z\right)$, can induce the change in vertical vorticity due to the restructuring of $\mathrm{PV}$ itself.

In Fig. $6 \mathrm{~b}$ and c, a low-level jet with $U_{\max }$ is located at $Z_{\max }$ upstream of the genesis site $\mathrm{V}$, and thus $\xi_{h}(=\alpha \cdot \partial U / \partial z)$ is negative above $Z_{\max }$. Assuming the air parcel moving along the isentropic surface is well-mixed with the environment, when it moves adiabatically along a constant isentropic surface that is above $Z_{\max }$ from $\mathrm{A}_{0}$ to $\mathrm{A}$ (Fig. 6b, c), its stability $\theta_{\mathrm{v}}$ decreases, whereas its baroclinity $\theta_{\mathrm{h}}$ increases. According to Eq. (8), its vertical vorticity should increase owing to the restructured PV.

In this section, the adiabatic development of vorticity associated with the TPV's genesis has been investigated from the PV perspective. It has been demonstrated that the near-surface warm air and the existence of an upstream low-level jet were favorable conditions for the SVD of the vortex. The former created a thermal background with the surrounding isentropic surfaces tilted towards the Earth's 
surface, while the latter caused decreasing static stability but increasing baroclinity of the air parcel when it moved down the slantwise isentropic surfaces. The development of vertical vorticity in this circumstance was due to the restructuring of the PV itself.

\section{Moist process and PV generation}

Previous studies have demonstrated that a robust thermal diurnal cycle is important for the variation in the local circulation over the TP, and most TPVs are generated at night $(\mathrm{Li}$

(a)18LT 26 Jun $\mathrm{w}_{700 \mathrm{hPa}}$

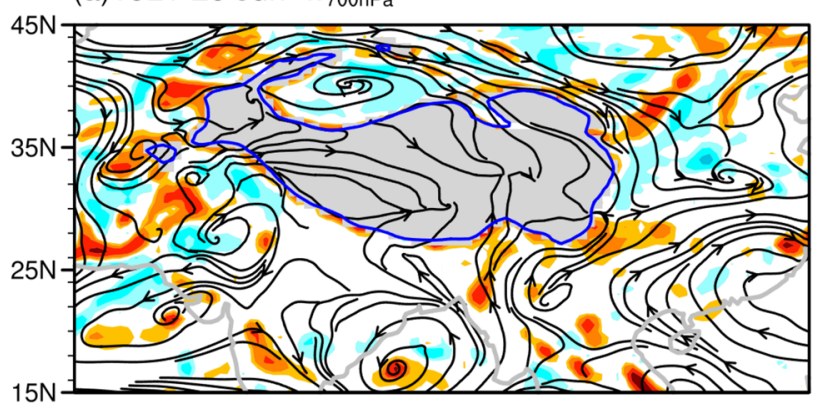

(b) 18LT 27 Jun $\mathrm{w}_{700 \mathrm{hPa}}$

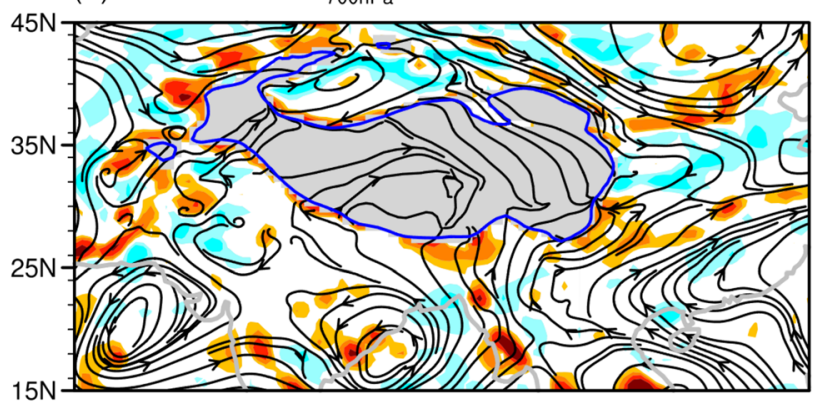

(c)00LT 28 Jun $\mathrm{w}_{700 \mathrm{hPa}}$

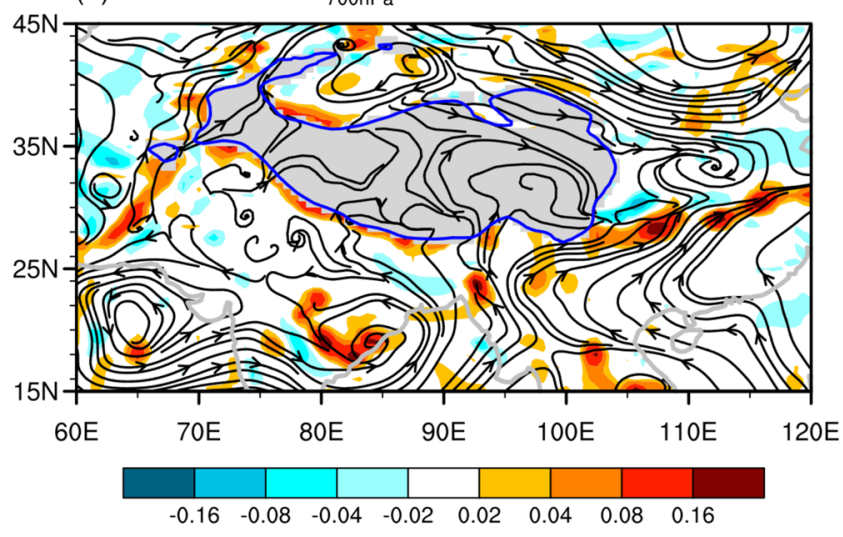

Fig. 7 Distribution of (a-c) 700-hPa vertical velocity $w$ (shading; units: $\mathrm{m} \mathrm{s}^{-1}$ ) and water vapor flux at $\sigma=0.75$ (streamlines); and (d-f) divergence of water vapor flux at $500 \mathrm{hPa}$ (shading; units: $10^{-5} \mathrm{~g} \mathrm{~s} \mathrm{~m}^{-1} \mathrm{~kg}^{-1}$ ) and the 24-h increment of equivalent potential temperature (dotted; units: $\mathrm{K}$ ) at $450 \mathrm{hPa}$, in which pale and dark dots et al. 2014a, 2018a; Curio et al. 2019). However, the diurnal cycle exists continually over the TP on a day-to-day basis, and yet TPV formation only occurs on certain days. The development of adiabatic vorticity alone cannot explain such a diurnal cycle. There must be a specific mechanism responsible for the formation of TPVs at night. In this section, we attempt to explore this aspect based on diabatic processes.

\subsection{Moist process and cloud development}

The current TPV under investigation developed in the late afternoon and formed at midnight on 27-28 June 2016. Ma

(d) $18 \mathrm{LT} 26$ Jun QV_div 500hPa $\& \Delta \theta_{\text {e } 450 \mathrm{hPa}}$

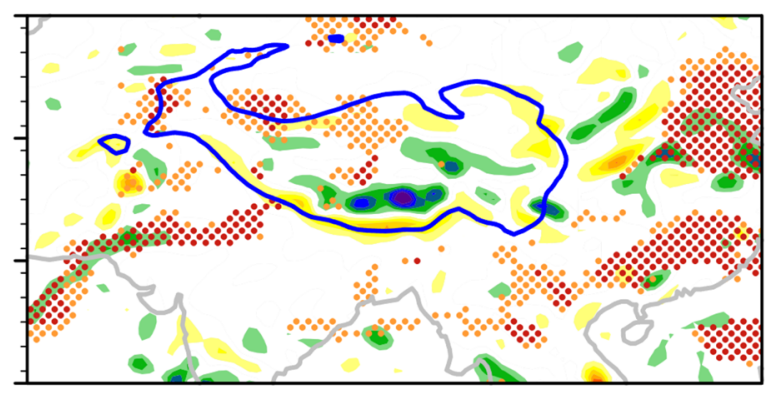

(e)18LT 27 Jun QV_div $500 \mathrm{hPa} \& \Delta \theta_{\mathrm{e}} 450 \mathrm{hPa}$

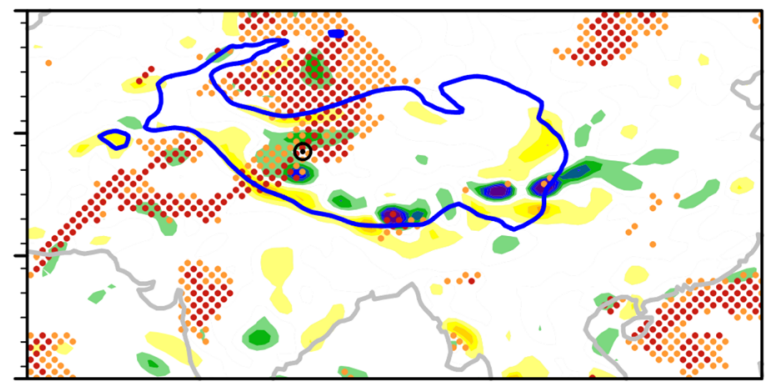

(f)00LT 28 Jun QV_div ${ }_{500 \mathrm{hPa}} \& \Delta \theta_{\mathrm{e}} 450 \mathrm{hPa}$

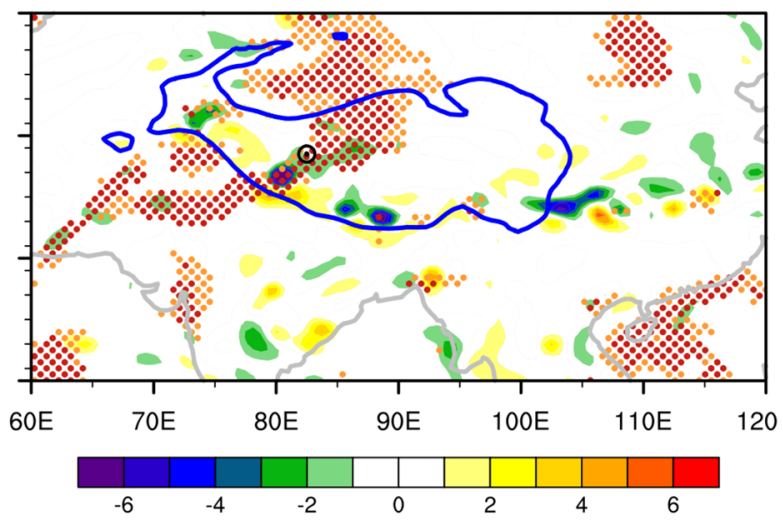

denote $>3 \mathrm{~K}$ and $6 \mathrm{~K}$, respectively, at (a, d) $1800 \mathrm{LT} 26$ June, (b, e) 1800 LT 27 June, and (c, f) 0000 LT 28 June. The thick blue contour indicates the area over $3000 \mathrm{~m}$. The black open dot denotes the location $\mathrm{V}$ of the vortex center 
(a)18LT 26 Jun TBB

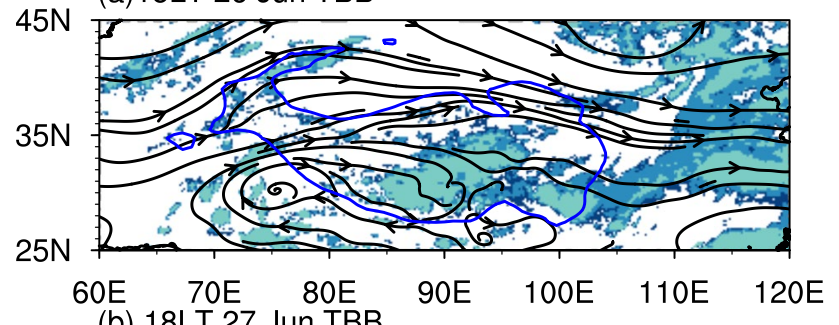

(b) $18 \mathrm{LT} 27$ Jun TBB
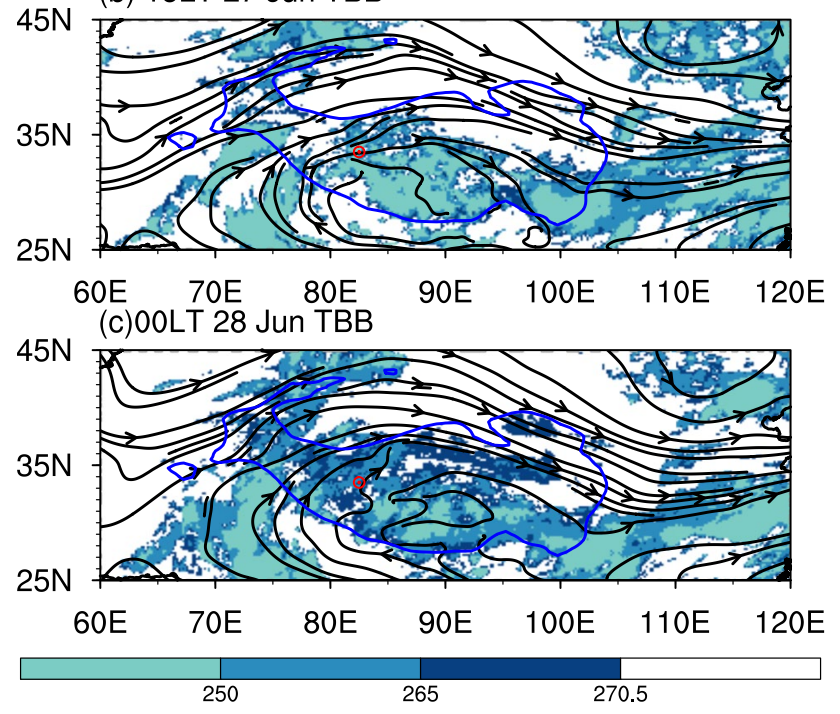

Fig. 8 Distributions of cloud brightness temperature (shading; units: $\mathrm{K})$ and $400-\mathrm{hPa}$ circulation (streamlines) at a $1800 \mathrm{LT} 26$ June, b 1800 LT 27 June, and c 0000 LT 28 June. The red open dot denotes the location $\mathrm{V}$ of the vortex center. The thick blue contour indicates the area over $3000 \mathrm{~m}$

et al. (2020) found that, although there was no precipitation during its development, cloud existed that contributed to its formation. However, where that cloud came from and how it contributed to the TPV's genesis are unknown. Here, we explore the moist processes that led to the formation of the TPV at midnight. The water vapor flux $\vec{Q}$ and its divergence $D$ can be calculated using the following relation:

$\vec{Q}=q \vec{V} / g$

and

$D=\nabla \cdot(q \vec{V}) / g$

where $\vec{V}$ is the horizontal wind vector, and $q$ is specific humidity. Figure 7 shows the evolution of the near-surface water vapor flux at $\sigma=0.75$ and the vertical velocity $w$ at $700 \mathrm{hPa}$ (left-hand column), as well as the divergence of water vapor flux at $500 \mathrm{hPa}$ (right-hand column). One day before the TPV's development, as the cyclonic circulation developed over the Arabian Sea and Bay of Bengal, southerly flow developed to their east, which transported water vapor from ocean to continent, with ascending motion developing over the southeastern boundary of the TP (Fig. 7a). At $500 \mathrm{hPa}$, as the southerly flow entered the TP area along its southern boundary (Fig. 4b), water vapor flux converged over its southern edges (Fig. 7d), while the western TP was relatively dry. By 1800 LT 27 June, as the tropical cyclones over the Arabian Sea and Bay of Bengal intensified and moved northwards, the associated water vapor flux from the northern Indian Ocean enhanced and advanced westwards towards the southwestern TP (Fig. 7b). At $500 \mathrm{hPa}$, as strong southwesterly flow invaded the southwestern TP and converged there (Fig. 4c), remarkable water vapor flux convergence occurred over the western TP (Fig. 7e). This situation continued to develop till the TPV formed at 0000 LT 28 June (Fig. 7c, f). Because the large-scale circulation in a convective atmosphere is closely related to the spatiotemporal distribution of the sub-cloud-layer entropy (Emanuel et al. 1994), high sub-cloud entropy is favorable for convective development during TPV genesis. Because entropy is proportional to equivalent potential temperature $\theta_{\mathrm{e}}\left[\theta_{\mathrm{e}}=\theta \exp \left(\mathrm{L}_{v} \mathrm{q} / \mathrm{C}_{p} T\right)\right]$, to understand the distribution of sub-cloud entropy over the TP, the 24-h increment of $\theta_{\mathrm{e}}$ at $450 \mathrm{hPa}$ is shown in Fig. 7d-f. The results demonstrate that the entropy in the lower troposphere over the TP did not change much on 26 June (Fig. 7d). However, it increased remarkably (by more than $6 \mathrm{~K}$ ) over western TP and to its southwest, where a pool of warm moist air established before the TPV's formation (Fig. 7e, f).

In accordance with the increasing water vapor transport, cloud developed rapidly over the western TP. Figure 8 presents the evolution of the cloud system and the streamline at $400 \mathrm{hPa}$. In a movie snapshot, the cloud movement over the TP exhibited a clockwise rotating pattern (not shown), in good agreement with the large-scale anticyclonic circulation at $400 \mathrm{hPa}$. On 26 June, clear sky was observed over the western TP and altostratus clouds occurred over the central and eastern TP (Fig. 8a). At 1800 LT 27 June, high clouds and some mid-level clouds developed near site V (Fig. 8b). At 0000 LT 28 June (Fig. 8c), low-level clouds dominated the western TP, in conjunction with the TPV's genesis. The corresponding evolution of CLWC along the longitude-height cross section averaged over the latitudinal span of $32.5^{\circ}-34.5^{\circ} \mathrm{N}$, where the TPV formed, is presented in Fig. 9. Before the TPV's development, the main CLWC was distributed over the western slopes of the TP below $450 \mathrm{hPa}$ and over the eastern TP where there was remarkable air ascent (Fig. 9a). By 1800 LT 27 June (Fig. 9b), the CLWC had increased rapidly above $400 \mathrm{hPa}$ over almost the entire TP, mainly distributed upstream of site V. Due to the westerly advection and high sub-cloud entropy (Fig. 7e), ascending motion developed evidently with a maximum of $5 \cdot 10^{-2} \mathrm{~ms}^{-1}$ at $400 \mathrm{hPa}$ and the cloud base was formed near $400 \mathrm{hPa}$ over the TPV's formation site V. By midnight 
Fig. 9 Longitude-vertical cross section averaged between $32.5^{\circ} \mathrm{N}$ and $34.5^{\circ} \mathrm{N}$ of cloud liquid water content (shading; units: $10^{-5} \mathrm{~kg} \cdot \mathrm{kg}^{-1}$ ) and zonal-vertical circulation (red vectors; units: zonal wind in $\mathrm{m} \cdot \mathrm{s}^{-1}$ and vertical velocity in $-50 \mathrm{~Pa} \times \mathrm{s}^{-1}$; reference vector is given in the bottom right) at a 1800 LT 26 June, b 1800 LT 27 June, and c 0000 LT 28 June. The right panels present the vertical profiles of vertical velocity $\left(\mathrm{cm} \cdot \mathrm{s}^{-1}\right)$ over the TPV center $\left(82-84^{\circ} \mathrm{E}\right)$. Gray shading shows the terrain altitude. The black dashed line denotes the location $\mathrm{V}$ of the TPV center
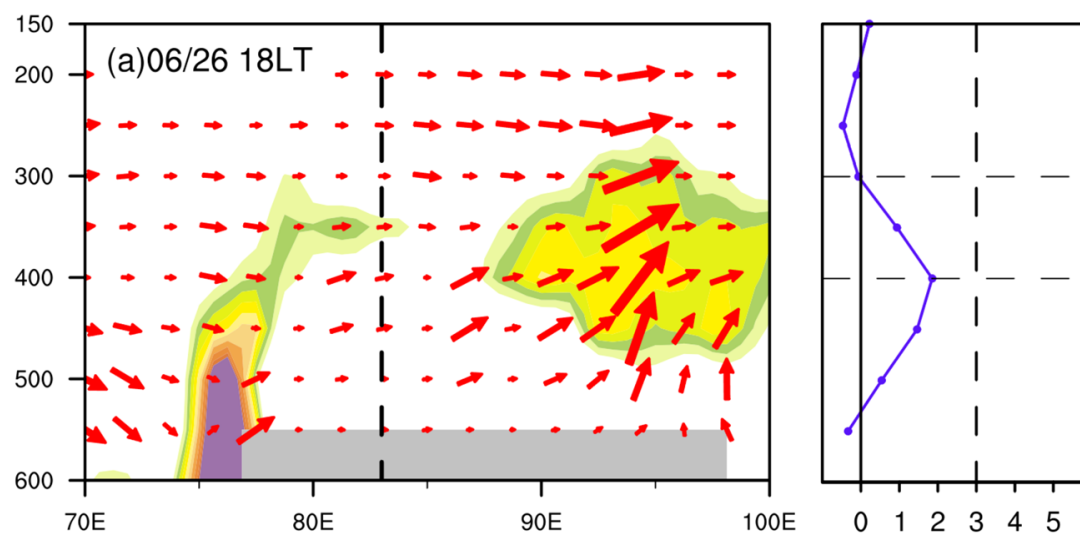

3.6 3.4
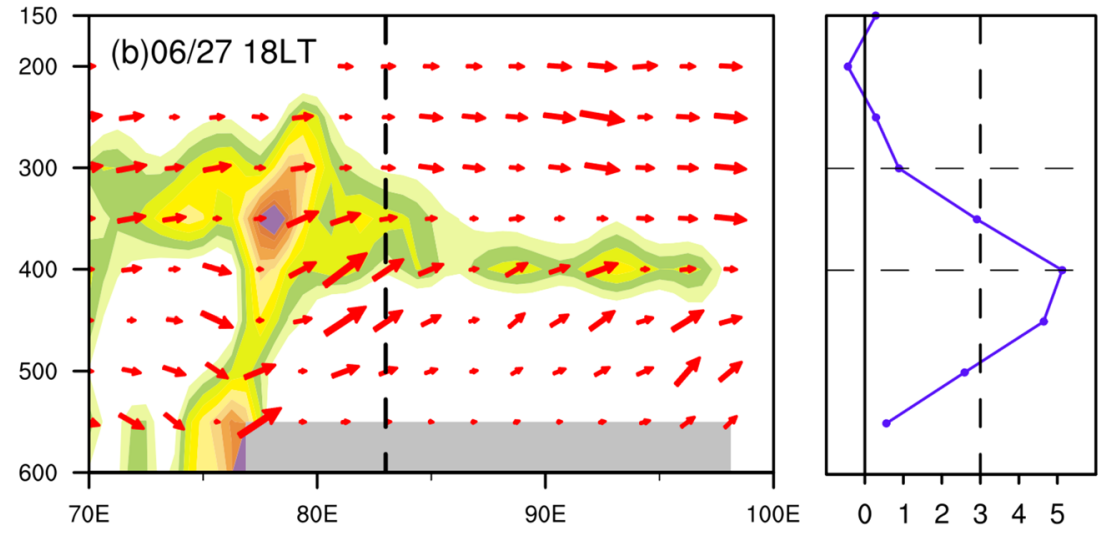

3.1

2.8 2.5 2.2
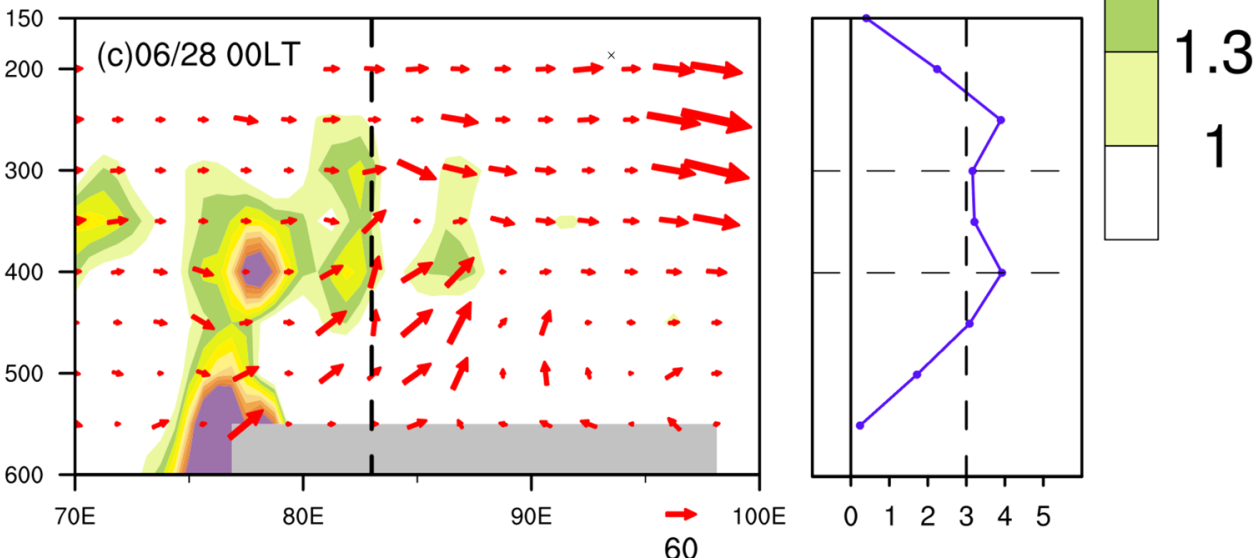
1.9 1.6 1.3 1
(Fig. 9c), as the CLWC remained high above $400 \mathrm{hPa}$ and the sub-cloud entropy continued to develop (Fig. 7f), remarkable ascending motion developed further upwards above $250 \mathrm{hPa}$ over the western TP in association with the TPV's formation.

\subsection{Effect of atmospheric heating on PV generation}

Figure 10a shows the evolution of vertical profiles of diabatic heating averaged over the vortex area $\left(32.5^{\circ}-34.5^{\circ} \mathrm{N}\right.$, $82.5^{\circ}-83.75^{\circ} \mathrm{E}$ ) on 26 June before the TPV's genesis (dashed curves), and on 27 June during the TPV's development (solid curves). Due to its high elevation, the heating profile over the TP exhibited a typical prominent thermal diurnal cycle on 26 June, with strong surface sensible heating in the daytime (green dashed profile) and longwave radiation cooling at night (red dashed profile). On 27 June, such a typical diurnal cycle was interrupted. In the daytime, the diabatic heating profile (green solid profile) was similar with that on 26 June (green dashed profile); starting from the evening, the diabatic heating between 400 and $200 \mathrm{hPa}$ over the TP increased rapidly (blue and red solid profiles). Further diagnosis indicates that such an increase was due to the moist processes (Fig. 10b): there was no moist process involved on 26 June. From 0000 LT 27 to 0000 LT 28 June, the heating associated with the moist process increased remarkably above $450 \mathrm{hPa}$. The maximum increase in heating occurred 


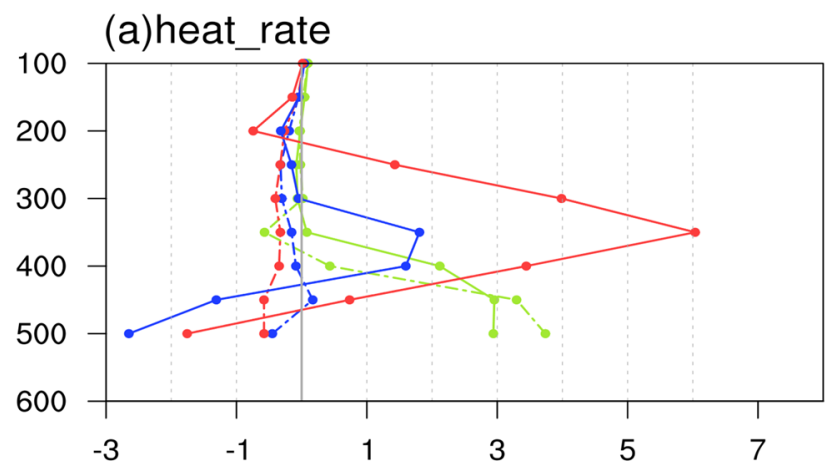

(b)heat_rate_moist

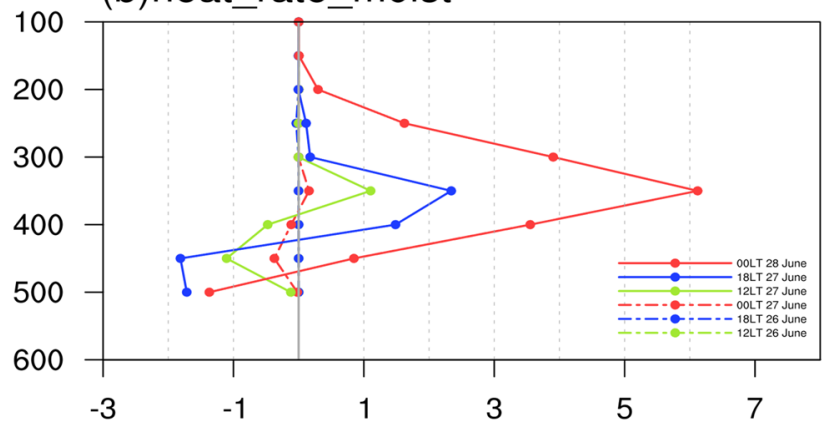

Fig. 10 Vertical profile at position V of the TPV center of (a) diabatic heating (units: $10^{-4} \mathrm{~K} \cdot \mathrm{s}^{-1}$ ) and (b) diabatic heating due to moist processes (units: $10^{-4} \mathrm{~K} \cdot \mathrm{s}^{-1}$ ) at $1200 \mathrm{LT}$ (green lines), $1800 \mathrm{LT}$ (blue lines), and 0000 LT (red lines). The dashed lines are for 26 June and 0000 LT 27 June, whereas the solid lines are for 27 June and 0000 LT 28 June. Refer to Ma et al. (2020)

at $350 \mathrm{hPa}$ : it was zero at $1800 \mathrm{LT} 26$ June but increased to $2 \times 10^{-4} \mathrm{~K} \mathrm{~s}^{-1}$ and $6 \times 10^{-4} \mathrm{~K} \mathrm{~s}^{-1}$ at $1800 \mathrm{LT} 27$ and 0000 LT 28 June, respectively. This is in accordance with the formation of cloud near 400 and $350 \mathrm{hPa}$ as shown in Fig. 9b and $\mathrm{c}$.

The rapid increase in nighttime diabatic heating in the lower troposphere is of significant for TPV genesis near the surface since, according to Eq. (1), a strong increase in diabatic heating with height can lead to prominent PV generation over the TP (Sheng et al. 2021), i.e.,

$\frac{\partial P}{\partial t} \propto \alpha(\mathrm{f}+\zeta) \frac{\partial \dot{\theta}}{\partial z}=\mathrm{F}$.

Usually, the thermally forced positive generation of $\mathrm{PV}$ $(F>0)$ over the TP at night $(\partial \dot{\theta} / \partial z>0)$ is compensated by the negative generation in the daytime $(\partial \dot{\theta} / \partial z<0)$, though not strictly symmetric, forming a typical diurnal cycle. When this diurnal cycle is interrupted with much stronger PV generation at night, the generation of a surface vortex becomes possible. Figure 11 shows the distribution of $F$ and the PV tendency over the TP at $500 \mathrm{hPa}$. The distribution pattern of the forcing $F$ was similar with that of the
PV tendency, but the magnitude of the tendency term was smaller because of PV advection and friction not being considered. On 26 June, the strong forcing by $F$ was located over the eastern and southern TP (Fig. 11a) owing to localized precipitation (not shown) that led to the PV generation there (Fig. 11d), which corresponded to the positive vorticity belt shown in Fig. 4b. Meanwhile, no forcing by $F$ or PV generation were observed over the western TP. The rapid intensification of diabatic heating near $400 \mathrm{hPa}$ on 27 June (Fig. 10a) greatly increased the nighttime $\mathrm{PV}$ forcing by $F$. At 1800 LT 27 June, as cloud formed near $400 \mathrm{hPa}$ over the western TP (Figs. 8b, 9b), noticeable positive $F$ forcing and a positive PV tendency appeared over the area (Fig. 11b, e). By midnight, as the airflow invading the southwestern TP and the associated water vapor flux converged upstream of the TPV site, in-situ low-level clouds had formed (Fig. 8c), high CLWC remained above $450 \mathrm{hPa}$ (Fig. 9c), and the $F$ forcing intensified strongly at the TPV site and in its upstream area (Fig. 11c). Finally, strong PV generated there correspondingly (Fig. 11f), and the TPV was formed in this region.

Therefore, the significance of the moist process in the TPV's genesis is evident. The convergence of water vapor flux over the western TP on 27 June resulted in a local increase in subcloud entropy. In conjunction with the development of vertical vorticity due to adiabatic PV restructuring, ascending motion developed, leading to the formation of low cloud and the release of latent heat there at night. The rapid increase with height of diabatic heating below the cloud base resulted in strong PV generation near the surface, and thus the TPV was generated over the western TP at night.

\section{Summary and discussion}

Through diagnostic analysis of the formation of a TPV event that generated over the western TP at midnight on 27-28 June 2016, when there was low cloud but no precipitation, this study has revealed several significant factors contributing to the formation of such an event. The results can be summarized as follows:

(1) An unusual circulation background. The TP is a strong heating source in June. At $500 \mathrm{hPa}$ climatologically, the westerly flow meanders over the TP with a geopotential ridge to its north and a deep trough developed to its south over the Bay of Bengal (Fig. 2a). In June 2016, before the formation of the TPV case investigated in the present study, an abnormal ridge at $500 \mathrm{hPa}$ developed over the northwestern TP along the midlatitude anomalous westerly flow (Fig. 2b). Strong tropical cyclones developed over the Bay of Bengal and Arabian Sea from the lower troposphere (Fig. 3) to the mid- troposphere (Fig. 2). An anomalous tropical easterly belt 

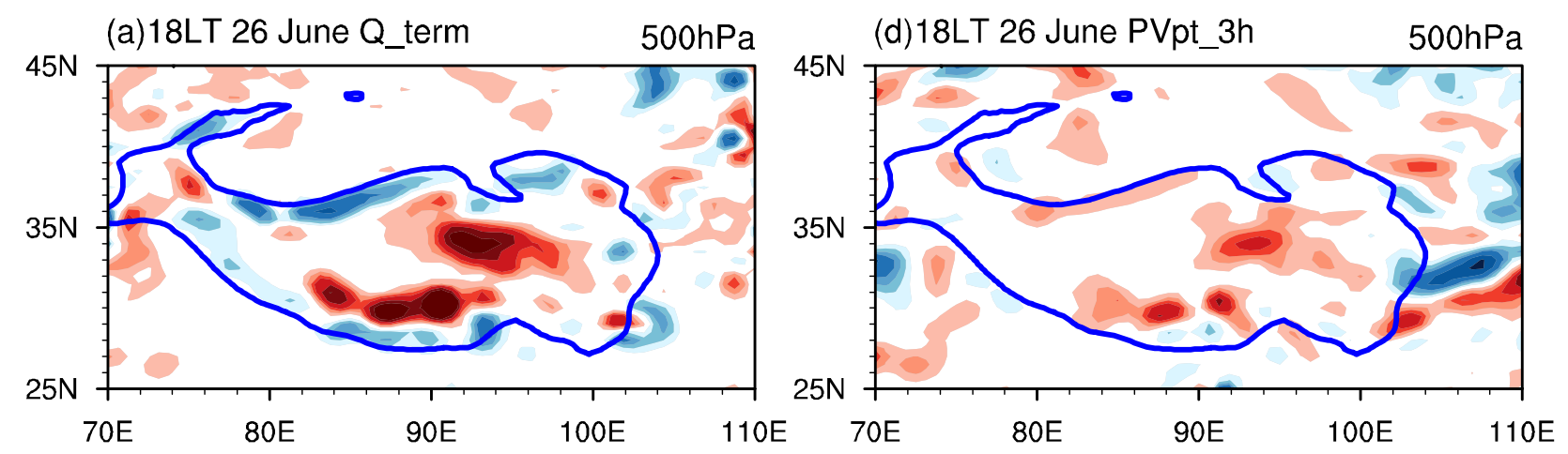

(b)18LT 27 June Q_term

(e)18LT 27 June PVpt_3h
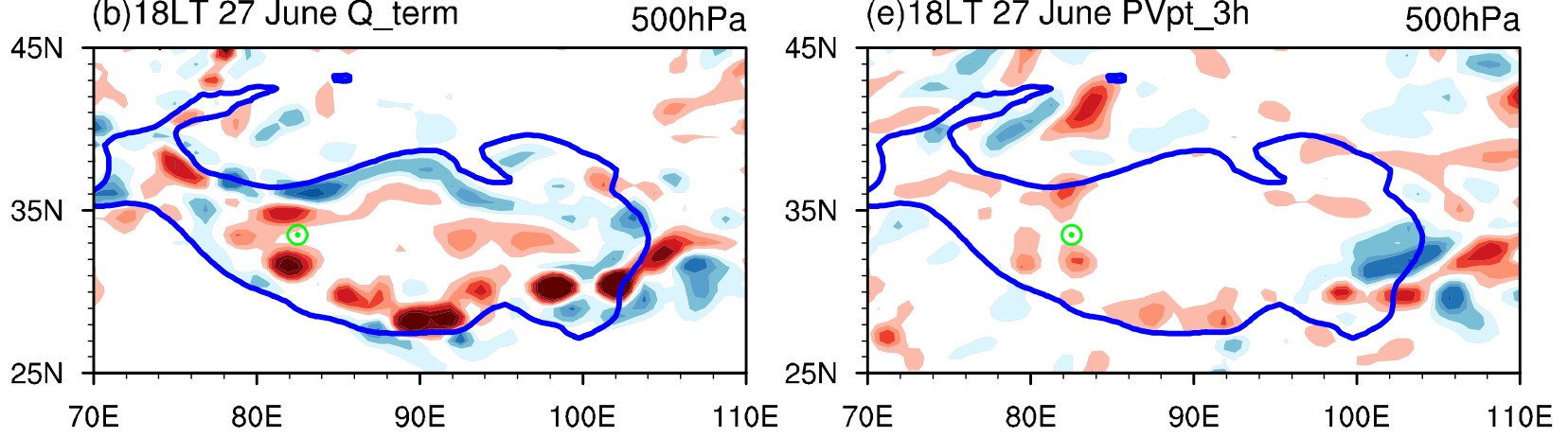

(c)00LT 28 June $Q$ term
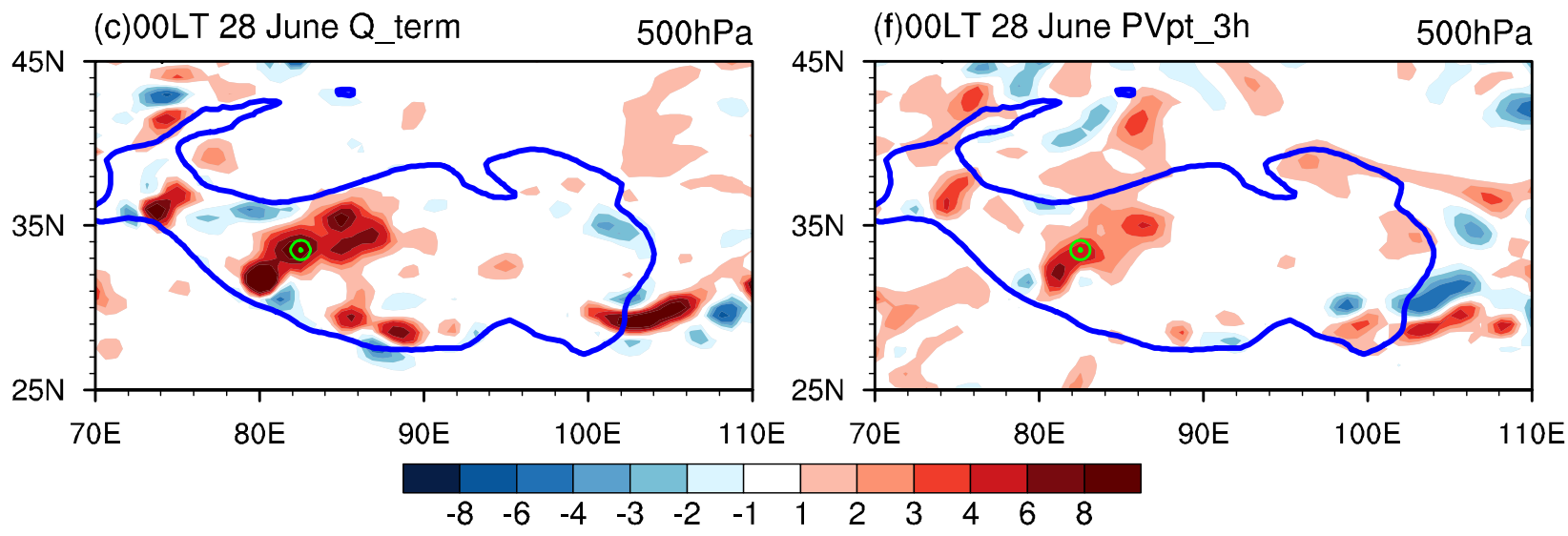

Fig. 11 Distributions at $500 \mathrm{hPa}$ of the (a-c) diabatic heating term of the PV equation (shading; units: $10^{-5} \mathrm{PVU} \cdot \mathrm{s}^{-1}$ ) and (d-f) PV tendency (shading; units: $10^{-5} \mathrm{PVU} \cdot \mathrm{s}^{-1}$ ) at (a, d) 1800 LT 26 June, (b, e) 1800 LT 27 June, and (c, f) 0000 LT 28 June. The green dot denotes the location of the vortex center. The thick blue contour indicates the area over $3000 \mathrm{~m}$ penetrated from the western Pacific to Africa, forming a zone of remarkable subtropical anticyclonic circulation between the tropical easterly flow and the midlatitude westerly flow (Fig. 2d), whilst at the same time a nearsurface warm center was located over the northwestern TP (Fig. 4f). As the tropical cyclones strengthened over the tropical oceans, the tropical easterly jet migrated northwards and its forefront merged with the midlatitude westerly flow over the Iranian Plateau, forming the western end of the tropical anticyclonic zone. Subsequently, the southwesterly flow at the western end of the subtropical anticyclone penetrated the interior of the TP and converged towards the near-surface warm center, inducing cyclonic circulation over the TPV's formation site V (Fig. 4c, d). Since the isentropic surfaces surrounding the near-surface warm center tilted downwards towards the center, when the air parcel of the southwesterly flow adiabatically converged towards the center, it slid downwards along the isentropic surfaces and its PV experienced a restructuring; its static stability decreased whilst the baroclinity increased, leading to slantwise development of vertical vorticity.

(2) The moist process played a significant role. The development of tropical cyclones over the Bay of Bengal and Arabian Sea in the lower troposphere transported abundant water vapor from the ocean northwards 
towards the TP, accompanied by ascending motion (Fig. 7a-c). At $500 \mathrm{hPa}$ and aloft, large quantities of water vapor were transported northwestwards by the tropical easterly flow, which subsequently converged to the southwest of the TP and its western interior (Fig. 7e, f). Consequently, the atmospheric entropy (Fig. 7) and low-level cloud (Fig. 8) over the western TP increased rapidly, and the area with high CLWC advanced from the southwestern border of the TP to its western region in the lower troposphere (Fig. 9). In association with the development of ascending motion, a cloud layer was produced with its base located near $400 \mathrm{hPa}$ (Fig. 9b, c).

(3) The typical diurnal cycle over the TP was interrupted by moist processes. The latent heat released due to the condensation of cloud liquid water near $400 \mathrm{hPa}$ over the TPV site was significant for the TPV's generation. Normally, the atmospheric diabatic heating in the surface layer over the TP at nighttime increases with height, mainly due to longwave radiation cooling, but decreases with height in the daytime owing to surface sensible heating. Therefore, the generation of PV at night [Eq. (9)] was canceled out by the degeneration of PV in the daytime, driving a usual diurnal cycle of circulation over the TP. The sudden increase in heating near $400 \mathrm{hPa}$ at night, such as the case on 27 June 2016, caused a strong increase in diabatic heating with increasing height in the sub-cloud layer (Figs. 10, 11ac), meaning remarkable positive PV generation thus occurred in situ (Fig. 11e, f) and the TPV was formed. When such PV generation is strong enough and cannot be compensated for by the degeneration of $\mathrm{PV}$ in the daytime, the TPV can then survive and even be transported eastwards along the prevailing westerly flow, affecting the weather further downstream.

Among the various factors that contributed to the formation of the TPV as revealed above, the near-surface warm center over the western TP is commonly observed. What made the difference from the climate mean was the development of the low-level jet, the convergent southwesterly flow over the southwestern TP, the in-situ high sub-cloud entropy, and the formation of low clouds there. These anomalous factors were mainly induced by the development of abnormally strong tropical easterly flow to the south of the TP, which was related to the development of tropical cyclones over the Arabian Sea and the Bay of Bengal. Therefore, it can be concluded that the formation of the TPV over the TP in late June 2016 was mainly due to the atmospheric circulation anomaly that developed in the tropics to the south of the TP, and driven by the associated atmospheric moist processes.

However, how the tropical circulation anomaly during this period generated and how the tropical cyclones developed over the northern Indian Ocean are not touched upon in this study. These issues are important and related to the variation in global circulation and land-atmosphere-ocean interaction in the area, which is deserving of further study. Moreover, it is important to acknowledge that the conclusions in this paper were obtained solely from a single case study. Verification based on climatological data is required and underway.

Acknowledgements This work was jointly supported by the National Natural Science Foundation of China (Grants 41730963 and 91937302), the Third Tibetan Plateau Scientific Experiment: Observations for Boundary Layer and Troposphere (Grant GYHY201406001), and the Strategic Priority Research Program of the Chinese Academy of Sciences (Grant XDB40030200).

Data availability The MERRA2 reanalysis dataset is available at https://disc.gsfc.nasa.gov/datasets?project=MERRA-2. The FY-2E meteorological satellite dataset is available at http://www.nsmc.org. $\mathrm{cn} / \mathrm{en} / \mathrm{NSMC} / \mathrm{Home} / \mathrm{Index} . \mathrm{html}$

\section{Declarations}

Conflict of interest On behalf of all authors, the corresponding author states that there is no conflict of interest.

Open Access This article is licensed under a Creative Commons Attribution 4.0 International License, which permits use, sharing, adaptation, distribution and reproduction in any medium or format, as long as you give appropriate credit to the original author(s) and the source, provide a link to the Creative Commons licence, and indicate if changes were made. The images or other third party material in this article are included in the article's Creative Commons licence, unless indicated otherwise in a credit line to the material. If material is not included in the article's Creative Commons licence and your intended use is not permitted by statutory regulation or exceeds the permitted use, you will need to obtain permission directly from the copyright holder. To view a copy of this licence, visit http://creativecommons.org/licenses/by/4.0/.

\section{References}

Chen Y, Zhang A, Zhang Y, Cui C, Wan R, Wang B, Fu Y (2020) A heavy precipitation event in the Yangtze River Basin led by an eastward moving Tibetan Plateau cloud system in the summer of 2016. J Geophys Res. https://doi.org/10.1029/2020jd032429

Curio J, Schiemann R, Hodges KI, Turner AG (2019) Climatology of Tibetan Plateau vortices in reanalysis data and a high-resolution global climate model. J Clim 32(6):1933-1950. https://doi.org/ 10.1175/jcli-d-18-0021.1

Emanuel K, Neelin J, Bretherton C (1994) On large-scale circulations in convecting atmospheres. Quart J R Meteorol Soc 120(519):1111-1143. https://doi.org/10.1002/qj.49712051902

Ertel H (1942) Ein neuer hydrodynamische wirbelsatz. Meteorol Z Braunschw 59:33-49

Feng X, Liu C, Rasmussen R, Fan G (2014) A 10-yr climatology of Tibetan Plateau vortices with NCEP climate forecast system reanalysis. J Appl Meteorol Climatol 53(1):34-46. https://doi.org/10. 1175/JAMC-D-13-014.1 
Feng X, Liu C, Fan G, Zhang J (2017) Analysis of the structure of different Tibetan Plateau vortex types. J Meteorol Res 31(3):514529. https://doi.org/10.1007/s13351-017-6123-5

Gelaro R, Mccarty W, Suárez MJ, Todling R, Zhao B (2017) The modern-era retrospective analysis for research and applications, version 2 (MERRA-2). J Clim 30(14):5419-5454. https://doi.org/ 10.1175/JCLI-D-16-0758.1

Hoskins B, McIntyre M, Robertson A (1985) On the use and significance of isentropic potential vorticity maps. Quart J R Meteorol Soc 111:877-946

Lhasa Workgroup for Tibetan Plateau Meteorology Research (1981) Research of $500 \mathrm{hPa}$ vortices and shear lines over the Tibetan Plateau in summer. Science Press, Beijing

Li G, Zhao B (2002) A dynamical study of the role of surface sensible heating in the structure and intensification of the Tibetan Plateau vortices. Chin J Atmos Sci 26:519-525

Li L, Zhang R, Wen M (2011) Diagnostic analysis of the evolution mechanism for a vortex over the Tibetan Plateau in June 2008. Adv Atmos Sci 28(4):797-808. https://doi.org/10.1007/ s00376-010-0027-y

Li L, Zhang R, Wen M (2014a) Diurnal variation in the occurrence frequency of the Tibetan Plateau vortices. Meteorol Atmos Phys 125(3-4):135-144. https://doi.org/10.1007/s00703-014-0325-5

Li L, Zhang R, Wen M, Liu L (2014b) Effect of the atmospheric heat source on the development and eastward movement of the Tibetan Plateau vortices. Tellus A. https://doi.org/10.3402/tellusa.v66. 24451

Li L, Zhang R, Wen M (2018a) Diurnal variation in the intensity of nascent Tibetan Plateau vortices. Quart J Roy Meteorol Soc 144(717):2524-2536. https://doi.org/10.1002/qj.3343

Li L, Zhang R, Wen M, Duan J (2018b) Development and eastward movement mechanisms of the Tibetan Plateau vortices moving off the Tibetan Plateau. Clim Dyn 52(7-8):4849-4859. https:// doi.org/10.1007/s00382-018-4420-Z

Lin Z, Guo W, Jia L, Yao X, Zhou Z (2020) Climatology of Tibetan Plateau vortices derived from multiple reanalysis datasets. Clim Dyn 55(7-8):2237-2252. https://doi.org/10.1007/s00382-020-05380-6

Liu H, Zhang S (1996) Moist potential vorticity and the three dimensional structrue of a cold front with heavy rainfall. Quart J Appl Meterol 7(3):275-284

Liu Y, Liu H, Liu P, Wu G (1999) The effect of spatially nonuniform heating on the formation and variation of subtropical high part II: land surface sensible heating and East Pacific subtropical high. Acta Meteorol Sin 57(4):385-396

Luo S, Yang Y (1992) A case study on numerical simulation of summer vortex over Qinghai-Xizang (Tibetan) Plateau. Plateau Meteorol 11:39-48

Luo S, Yang Y, Lu S (1991) Diagnostic analyses of a summer vortex over Qinghai-Xizang Plateau for 29-30 June 1979. Plateau Meteorol 10:1-11

Ma T, Liu Y, Wu G, Mao J, Zhang G (2020) Potential vorticity diagnosis on the foemation, development and eastward movement of a Tibetan Plateau vortex and its influence on the downstream precipitation. Chin J Atmos Sci 44(3):20-34

Shao X, Li S, Liu N, Song J (2018) The Madden-Julian oscillation during the 2016 summer and its possible impact on rainfall in China. Int J Climatol 38:2575-2589

Shen R, Reiter E, Bresch J (1986) Some aspects of the effects of sensible heating on the development of summer weather system over the Qinghai-Xizang Plateau. J Atmos Sci 43:2241-2260

Sheng C, Wu G, Tang Y, He B, Xie Y et al (2021) Characteristics of the potential vorticity and its budget in the surface layer over the
Tibetan Plateau. Int J Climatol 41(1):439-455. https://doi.org/10. 1002/joc.6629

Sun S, Li D, Liu LL, Wang ZY, Yin YZ (2017) Global major weather and climate events in 2016 and the possible causes. Meteorol Mon 43:477-485

Tao SY (1980) Torrential rain in China. China Science Press, Beijing

Tao SY, Wei J (2007) Correlation between monsoon surge and heavy rainfall causing flash-flood in southern China in summer. Meteor Mon 33:10-18

Tian S, Duan A, Wang Z, Gong Y (2015) Interaction of surface heating, the Tibetan Plateau vortex, and a convective system: a case study. Chin J Atmos Sci 39(1):125-136

Wang B (1987) The development mechanism for Tibetan Plateau warm vortices. J Atmos Sci 44:2978-2994

Wu G, Liu H (1997) Vertical vorticity development owing to downsliding at slantwise isentropic surface. Dyn Atmos Oceans 27(1-4):715-743

Wu G, Liu H (1999) Complete form of vertical vorticity tendency equation and slantwise vorticity development. Acta Meteorol Sin 57:1-15

Wu G, Cai Y, Tang X (1995) Moist potential vorticity and slantwise vorticity development. Acta Meteorol Sin 53(4):387-405

Wu D, Zhang F, Wang C (2018a) Impacts of diabatic heating on the genesis and development of an inner Tibetan Plateau vortex. J Geophys Res 123(20):11691-11704. https://doi.org/10.1029/ 2018jd029240

Wu G, Liu Y, He B, Bao Q, Wang Z (2018b) Review of the impact of the Tibetan Plateau sensible heat driven airpump on the Asian summer monsoon. Chin J Atmos Sci 42:488-504. https://doi.org/ 10.3878/j.issn.1006-9895.1801.17279

Wu G, Ma TT, Liu Y, Jiang Z (2020) PV-Q Perspective of cyclogenesis and vertical velocity development downstream of the Tibetan Plateau. J Geophys Res. https://doi.org/10.1029/2019jd030912

Yanai M, Li CF, Song ZS (1992) Seasonal heating of the Tibetan Plateau and its effects on the evolution of the Asian summer monsoon. J Meteorol Soc Jpn 70:419-434

Ye D, Gao Y (1979) The Tibetan plateau meteorology. China Science Press, Beijing

Zhang SL, Tao SY, Zhang QY, Wei J (2002) Large and meso- $\alpha$ scale characteristics of intense rainfall in the mid and lower reaches of the Yangtze River. Chin Sci Bull 47:467-473

Zhang QY, Tao SY, Zhang SL (2003) The persistent heavy rainfall over the Yangtze River Valley and its associations with the circulations over the East Asian during summer. Chin J Atmos Sci 27:1018-1030

Zhang FM, Wang CH, Pu ZX (2019) Genesis of Tibetan plateau vortex: roles of surface diabatic and atmospheric condensational latent heating. J Appl Meteorol Clim 58:2633-2651. https://doi.org/10. 1175/jamc-d-19-0103.1

Zhang GS, Mao JY, Wu GX, Liu YM (2021) Impact of potential vorticity anomalies around the eastern Tibetan Plateau on quasibiweekly oscillations of summer rainfall within and south of the Yangtze Basin in 2016. Clim Dyn 56(3):1-23. https://doi.org/10. 1007/s00382-020-05505-x

Zhou CL, Wang KC, Qi D (2018) Attribution of the July 2016 extreme precipitation event over China's Wuhan. Bull Am Meteorol Soc 99:S107-S112. https://doi.org/10.1175/BAMS-D-17-0090.1

Publisher's Note Springer Nature remains neutral with regard to jurisdictional claims in published maps and institutional affiliations. 